\title{
State-space modeling of multi-decadal mark-recapture data reveals low adult dispersal in a nursery-dependent fish metapopulation
}

Lecomte Jean-Baptiste ${ }^{1}$, Le Pape Olivier ${ }^{2,}{ }^{*}$, Baillif Hélène ${ }^{2}$, Nevoux Marie ${ }^{3}$, Vermard Youen ${ }^{4,5}$, Savina-Rolland Marie ${ }^{5,6}$, Veron Matthieu ${ }^{2}$, Lehuta Sigrid ${ }^{7}$, Hunter Ewan ${ }^{8}$, Rivot Etienne ${ }^{9}$

${ }^{1}$ AGROCAMPUS OUEST, 124109, Research Unit Ecology and Ecosystem Health, 65 rue de Saint Brieuc, CS 84215, Rennes, France

2 AGROCAMPUS OUEST, 124109, Research Unit Ecology and Ecosystem Health, Rennes, France

3 INRA, UMR Ecologie et Santé des Ecosystèmes, 65 rue de St Brieuc, Rennes, France

4 IFREMER, Unité EMH, Nantes, France

5 IFREMER, Unité d'Halieutique Manche Mer du Nord, F-62321, Boulogne, France

6 IFREMER, Laboratoire Ressources Halieutiques - Fisheries Resources Laboratory, Lorient, France

7 Ifremer, Ecologie et Modèles pour l'Halieutique, Nantes, France

${ }^{8}$ Centre for Environment Fisheries and Aquaculture Science, 41843, Lowestoft, Suffolk, United

Kingdom of Great Britain and Northern Ireland

${ }_{9}^{9}$ Agrocampus Ouest, UMR 0985 INRA / Agrocampus Ouest ESE, Agrocampus, Ecologie Halieutique, 65, rue de St Brieuc, Rennes, France

* Corresponding author : Olivier Le Pape, email address : Olivier.le.pape@agrocampus-ouest.fr

\begin{abstract}
:
Quantifying connectivity within fish metapopulations is an important component in understanding population dynamics and providing an evidence base for assessment and management. We investigate meta-population connectivity of the common sole (Solea solea L.) in the Eastern English Channel (EEC). The EEC common sole stock is currently assessed as a single and spatially homogeneous population but connectivity induced through adult movements within this stock and with nearby stocks remains unknown. To fill this knowledge gap, we developed a state-space mark-recovery model, designed to estimate adult connectivity, using mark-recapture data from multiple release experiments from 1970 to 2018 across the EEC and adjacent management areas. The model estimates seasonal fish movements between five predefined areas, Western English Channel, Eastern English Channel (split into three discrete sub-areas) and North Sea. Over 32000 fish were tagged, 4036 of which were recovered via fisheries. Our results suggest minimal large-scale adult movements between these areas: movements among spatial units within the EEC were very low with even lower levels of immigration from areas adjoining the EEC. Our results support the hypothesis of segregated populations within the EEC. The importance of accommodating population substructure in the fisheries management is considered.
\end{abstract}

Keywords : Population structure, capture-mark-recovery, adult connectivity, multi-event modeling, Solea solea L., Eastern English Channel 


\section{$\begin{array}{lll}35 & 1 & \text { INTRODUCTION }\end{array}$}

36 Movements of individuals determine connectivity between habitats, control meta-

37 population dynamics (Hanski 1998; Benhamou 2014) and resilience of populations to

38 natural and anthropic stressors. Understanding the movement and dispersal patterns of

39 wild animals at every stage in their life cycle is therefore critical for a full understanding

40 of population dynamics and the subsequent provision of an evidence base for population

41 assessment and management.

42 In fisheries, an accurate definition of the spatial structure of fish populations is necessary

43 for fish stock assessment and for setting appropriate fisheries management strategies

44 (Kutkuhn 1981; Smith et al. 1990; Begg \& Waldman 1999; Fogarty \& Botsford 2007). A

45 misspecification of the spatial limits of a stock can lead to biased estimates of population

46 vital rates (Cadrin et al. 2014; Kerr et al. 2017). Dispersal process must be addressed at

47 all life-history stages to accurately assess the spatial and temporal delineation of

48 populations and to accurately specify spatial management measures that could

49 potentially target specific areas and life stages (e.g. protecting nursery areas and

50 spawning aggregations, Fogarty and Botsford 2007).

51 Recent studies have employed a wide variety of tools and methods to assess

52 connectivity within populations (Le Bris et al. 2017; Rogers et al. 2017; Moreira et al.

53 2018). Genetic studies using genetic markers such as microsatellites (Cuveliers et al.

54 2012; Jasonowicz et al. 2016; Martinez et al. 2017) or single nucleotide polymorphism

55 (Milano et al. 2014; Laconcha et al. 2015; Bekkevold et al. 2015) are often used to

56 assess the spatial structure of a population and reproductive isolation within populations 
57 (Östman et al. 2017; Marandel et al. 2017). Otoliths are also extensively used in 58 connectivity studies, either through otolith morphology (Bacha et al. 2016; Hüssy et al. 59 2016; Mahe et al. 2016) or otolith chemistry (Tanner et al. 2016; Callicó Fortunato et al. 60 2017; Régnier et al. 2017; Moreira et al. 2018). Morphometry and meristics (Allaya et al. 61 2016; Sley et al. 2016), parasites (Catalano et al. 2014; MacKenzie \& Abaunza 2014) 62 and life history traits (Begg et al. 1999; Erlandsson et al. 2017; Du Pontavice et al. 2018;

63 Randon et al. 2018) have also been used to assess stock structure. In the past decade, 64 stock delineation studies have resulted in revised stock boundaries for numerous stocks 65 (e.g. blue whiting Mahe et al. 2007, Atlantic cod Zemeckis et al. 2014, and horse mackerel Abaunza et al. 2008).

67 Although the information derived from mark-recapture experiments is limited (e.g. they 68 cannot be used to quantify gene flow, Cadrin et al. 2014), they have nevertheless 69 proven useful for the investigation of fish movements and the spatial structure of 70 populations (Howe \& Coates 1975; Hilborn 1990; Gillanders et al. 2001; Patterson III et 71 al. 2001; McGarvey \& Feenstra 2002; Adlerstein et al. 2008; Cadrin et al. 2014; 72 Hanselman et al. 2014; Le Bris et al. 2017; Liljestrand et al. 2019). When considering 73 commercial fish stocks, tagging data generally consist of mark-release experiments 74 conducted on scientific surveys, with tag-recovery facilitated via the fisheries, the latter 75 largely dependent on volunteer reporting by the harvesters. A weakness of such data is 76 that the detection probability is usually unknown, and non-reporting can be substantial 77 (Henny \& Burnham 1976; Frusher et al. 2001; Pollock et al. 2002; Cadigan \& Brattey 78 2003, 2006). However, ancillary information is often available (McGarvey \& Feenstra 79 2002). Catch and fishing-effort data are collected for most exploited stocks. Classical 80 stock assessment models (e.g. Virtual Population Analysis or Statistical Catch-at-Age 
81 Analysis) typically provide estimates of total and fishing mortality, and thereby total 82 abundance. Such information can be used as input in the analysis of tagging data of 83 harvested fish populations (McGarvey \& Feenstra 2002).

84 The common sole (Solea solea, L.) is a flatfish substantively harvested in the Western 85 English Channel to the North Sea (ICES 2017). Today, stock assessment is conducted 86 separately for three ICES stock divisions (VIIe, VIId, IV; ICES 2017). The Eastern 87 English Channel (EEC, ICES division VIId) stock, managed as one homogeneous 88 population, has been overexploited over the last ten years (ICES 2017). Dispersal of the 89 subadult components has been described: the larvae drift passively over short distances 90 to local coastal nurseries (Rochette 2011), where the juveniles remain prior to migration 91 offshore at maturity (Riou et al. 2001), where the fish reproduce and enter the fishery. 92 Observed contrast in key life history traits (density-at-age and length-at-age data) have 93 suggested potential spatial structuring within the adult component of the EEC common 94 sole stock within three discrete spatial areas (Du Pontavice et al. 2018; Randon et al. 95 2018). However, the movements of adult sole between these areas remain largely 96 unknown. Here we have drawn on an extensive mark-recapture database collected over 9749 years to analyze fish movements and assess connectivity of the adult common sole 98 population within the EEC and adjacent management areas. We tested the hypothesis 99 of metapopulation structure within the EEC and estimated the level of mixing between 100 sub-populations. For that purpose, we developped a capture-recapture model (Royle et 101 al. 2013; McCrea \& Morgan 2014) built in a state-space model framework (recently 102 reviewed in Aeberhard et al. 2018 in the context of fisheries) to estimate adult and 103 subadult movement probabilities. Finally, based on our observations, we consider the 104 implications for management of the common sole stock in the EEC (and more widely) of 
105 acknowledging and incorporating population substructure in management and 106 assessment.

1072 MAterials ANd Methods

$108 \quad 2.1$ Spatial structure

109 The spatial structure of the common sole population along the English Channel is 110 analyzed using five areas (Figure 1): the Western Channel (WC), the North Sea (NS) 111 and three areas for the EEC: English coast of the Eastern English Channel (UK), 112 Southern French coast (FrW) and Northern French coast of the Eastern English Channel 113 (FrE). The WC area is based on an existing spatial management unit (VIle ICES 2017). 114 The spatial management unit IV currently used for stock assessment in the North Sea 115 (ICES 2017) is divided into three spatial subunits. Our study is restricted to the spatial 116 subunit IVc (ICES 2017) which contains the major part of the common sole commercial 117 catches in the North Sea. The division of the EEC into three areas (UK, FrW, FrE) is 118 based on the occurrence of natural barriers of habitat unsuitable for common sole 119 (Rochette et al. 2012). These natural barriers consist of deep gravel grounds, which 120 occur centrally in the EEC (separating UK from FrW \& FrE), and wide rocky reefs from 121 the coasts out into deeper waters (separating FrW from FrE). These natural delineations 122 could potentially define the spatial structure of the common sole population within the 123 EEC and have recently been used to study its connectivity in the EEC (Du Pontavice et 124 al. 2018; Randon et al. 2018).

\section{$125 \quad 2.2$ Data Collection}

126 The dataset collates four mark-recapture experiments carried out by (i) the Center for 127 Environment Fisheries and Aquaculture Science (CEFAS, UK) from 1955 to 1985 and 128 2002 to 2007 (Burt \& Millner 2008) and (ii) the French Research Institute for Exploitation 
129 of the Sea (IFREMER, France) from 1976 to 1980 and 2016 to 2018 (Table 1, Figure 2).

130 For each release experiment, Petersen discs were used (Burt \& Millner 2008). Discs are

131 uniquely numbered and are securely attached to the dorsal flank of the fish. Adults and

132 subadults were released close to the capture position as soon as was possible after

133 capture. Recaptured marked fish were recovered by fishermen, who provided dates and

134 spatial coordinates of the recaptures. To assess temporal variations in key model

135 parameters (see below), the entire dataset was divided into four release experiments

136 denoted (1) CEFAS 1970 from 1970 to 1985, (2) CEFAS 2002 from 2002 to 2007, (3)

137 IFREMER $_{1976}$ from 1976 to 1980 and (4) IFREMER $_{2016}$ from 2016 to 2018 (Tables 1 and

138 2). Data collected before 1970 were discarded, as information was not sufficient to

139 estimate fish movements from mark-recovery data (i.e. no reliable estimate of fishing

140 mortality, see section 2.4.2). Recaptured fish with no release or recovery position or date

141 of recovery data were discarded. The mark-recapture dataset consists of 32739

142 released and 7010 recovered fish with known dates and areas of release and recovery

143 respectively.

\section{$144 \quad 2.3 \quad$ Time at liberty and time step}

145 A discrete 4 months time step was used in our modeling approach, based on the life 146 cycle of the adult common sole (Rochette 2011): spawning (February to May), foraging 147 (June to September) and overwintering (October to January). For each individual, the 148 time at liberty (time elapsed between the date of release and the date of recapture) was 149 recorded. The time at liberty was computed in a number of time steps (Table 1 and 150 Figure 3). Individuals recovered within the time step of release were removed from the 151 analysis (2974 fish, $7 \%$ of released fish). 


\section{$152 \quad 2.4$ Modeling approach}

\section{$153 \quad 2.4 .1$ Core modeling structure}

154 The final dataset used in the modeling approach consists of 32739 released and 4036

155 recovered fish with the following associated information (individual based): dates and 156 areas of release and recovery and release experiment. The dataset was analyzed

157 through a multi-event mark-recapture modeling approach (Pradel et al. 2005) built in a 158 state-space modeling framework that accounts for both processes and observation 159 errors. The process model tracks the history of each individual released fish on a 160 'seasonal' (4-month discrete time step) basis. The trajectory of each individual starts 161 with the release event, for which the date and areas are assumed to be recorded without 162 errors. In our multi-event model, we consider 15 potential states for the true fate of 163 individuals at each time step (Figure 4):

$$
\left\{A_{W C}, A_{U K}, A_{F r W}, A_{F r E}, A_{N S}, F_{W C}, F_{U K}, F_{F r W}, F_{F r E}, F_{N S}, M_{W C}, M_{U K}, M_{F r W}, M_{F r E}, M_{N S}\right\}
$$

165 State $A$ relates to live fish, state $F$ relates to fish dying by fishing and state $M$ relates to 166 fish dying of natural causes, all located respectively in areas WC, UK, FrW, FrE, NS,

167 Figure 1). At any time step $t$, a fish can be in one (and only one) of those 15 states. The 168 transition between time step $t$ and $t+1$ consists of a three-step series of transitions 169 representing ecological and observation processes (Figure 4):

1. Movement process. Any alive fish at time $t$ can remain in its current area $i(i=1, \ldots, 5$ ) or move to another area $j(j=1, \ldots, 5)$ between $t$ and $t+1$. The dispersion of all fish present in the area $i$ at time $t$ is modeled through a Multinomial distribution with movement probabilities $\phi_{(i, j)}$ and $\sum_{j=1}^{5} \phi_{(i, j)}=1$ (see details hereafter).

2. Survival. The model assumes that mortality occurs after movements. After movements, a fish can survive or die from either natural mortality or fishing mortality between $t$ and $t+1$. For each individual, this transition is modeled as a Multinomial distribution with survival rate, mortality rate by fishing or mortality rate by natural causes as parameters (denoted $\tau^{s}, \tau^{f}$ and $\tau^{m}$, respectively; see details hereafter). 
1793 3. Observation process. The observation process (that ultimately defines the likelihood) links observation to the true biological state of each individual at time $t$. Only fish caught by the fishery can potentially be observed. Alive fish or fish dead from natural causes are unobservable. Once a marked fish is caught by the fishery, it can eventually be declared. The declaration of a marked fish caught is modeled through a Bernoulli distribution with declaration rate $\Psi$ (see details hereafter).

\subsubsection{Parameterization}

186 We tested several versions of the model accounting for different levels of spatial and 187 temporal variations in the parameters. Below, we detail the parameterization used in the 188 full model that accounts for seasonal movements, spatial heterogeneity and inter-annual 189 variation of survival, and survey-specific declaration rate (model 1, Table 3). Other 190 challenging models are detailed in section 2.4.3.

Movement process

192 Probabilities of movement $\phi_{(i, j, s)}$ are estimated separately for each pair of departure ( $193 i=1, \ldots, 5)$ and arrival areas $(j=1, \ldots, 5)$ and for each season $s(s=1, \ldots, 4)$. No variability 194 between years is considered. Movement parameters from the WC to the NS, and from 195 the NS to the WC are set to 0 and are not estimated (Figure 1). No fish were observed 196 making these two migrations patterns in a single time step (i.e. 4 months). Therefore, it 197 was assumed that the large distance separating the two areas does not allow for such 198 movement in one time step.

\section{Survival process}

200 Survival probabilities for each time step are fixed and assumed known without errors, 201 defined as:

202

$$
\begin{aligned}
\tau^{f} & =\frac{f}{f+m}(1-\exp (-(f+m)) \\
\tau^{m} & =\frac{m}{f+m}(1-\exp (-(f+m)) \\
\tau^{s} & =1-\left(\tau^{f}+\tau^{m}\right)
\end{aligned}
$$


203 where $\tau^{f}$ is the probability of death by fishing, $\tau^{m}$ is the probability of natural fish death 204 and $\tau^{s}$ is the probability of survival. $m$ and $f$ respectively are natural and fishing mortality 205 (per time step of 4 months) as directly derived from published stock assessment 206 evaluations (ICES 2017). For the three ICES areas (IVc, VIId and VIle) the spatially and 207 temporally constant natural mortality was fixed to $m=0.1 \times$ timestep $^{-1}$ (ICES 2017). 208 Fishing mortality rate $f$ was also considered known but with years and spatial variability. 209 Available information from stock assessment differ among areas (ICES 2017): estimates 210 of fishing mortality are available since 1955 for the NS area (ICES division IVc), from 2111969 for the WC area (ICES division VIle) and from 1982 for the UK, FrW, FrE areas 212 jointly (ICES division VIId) (Figure 5). The data collected before 1970 were discarded 213 because no reliable estimate of $f$ in the EEC could be found before 1970. In order to use 214 the longest time series of release data, we assumed that fishing mortality was equal in 215 areas Vlle and VIld between 1970 to 1981 . Temporal variations were smoothed to limit 216 the influence of uncertainty that surrounds short term (year-to-year) variations in 217 estimates of fishing mortality (Figure 5). Preliminary analysis demonstrated that 218 smoothed time series of $f$ improve numerical stability of dispersal estimates. The 219 mortality rates were allocated to each time step within the same year by considering that $220 m$ and $f$ were homogeneous among seasons within a year.

\section{Declaration}

222 The probabilities that marked fish caught by the fishery are declared (and then 223 observed) are estimated, and considered to be variable between release experiments 224 (but spatially homogeneous and constant among seasons). 


\section{$225 \quad$ 2.4.3 Hypotheses testing and sensitivity analysis}

226 The full model (model 1, Table 3) accounts for (i) a movement process with parameters 227 (estimated) that vary between seasons, (ii) yearly and spatially varying survival (fixed 228 parameters), and (iii) declaration rates (estimated parameters) considered to be variable 229 between release experiments. In all models, to avoid confusion between parameters and 230 ensure stable numerical results in the maximum likelihood procedure, estimated 231 parameters are the movement probabilities and the declaration rates, and all mortality 232 rates (fishing and natural) are considered known.

233 The existence of dispersal patterns that differ among seasons is tested by fitting models 234 with no variability of movement probabilities between seasons (models 2, 5 and 7, Table 235 3) and comparing the results obtained with the full model (model 1, Table 3). The 236 variation of the declaration rates between release experiments is tested by fitting a 237 model parameterized with a unique (but still estimated) declaration rate over the full time 238 series (model 3, Table 3). The existence of inter-annual differences in movements 239 during the time series is assessed by fitting separate models to the full time series of 240 data (1970-2018; model 1, Table 3) and to the most recent (2002-2018; model 8, Table 2413 ) and historical time series only (1970-1998; model 9, Table 3). Hypotheses made on 242 the fishing mortality (considered known in our model) are critical. We therefore also 243 assessed the robustness of our results to the quantity of expertize on the spatio244 temporal variability of fishing mortality brought into the model. Models with less refined 245 hypotheses were fitted using: (i) fishing mortality constant over time but different 246 between areas, computed as the mean of fishing mortality over time series per area 247 (models 4 and 5, Table 3), and (ii) fishing mortality constant over time and 
248 homogeneous in space, calculated as the mean over areas and times series (models 6 249 and 7, Table 3).

\section{$250 \quad$ 2.4.4 Model fit and selection}

251 All models were built and fitted using the E-SURGE program (version 1.9.0, Choquet 252 and Nogue 2010). Details about the implementation of the model in E-SURGE are given 253 in Appendix A. Parameters (movement and declaration rates) were estimated in the 254 maximum likelihood framework (MLE). The data consist in the sequence of observation 255 events for all individuals, starting with $i$ (the area of release, $i=1, \ldots, 5$ ) at the tagging 256 event, and ending with $j$ (the area of recovery, $j=1, \ldots, 5$ ) when the fish is recaptured and 257 declared (with a series of 0 between the tagging and the recapture event as the fish can 258 only be recaptured once) or ending with a series of 0 for fish that are never recaptured.

259 The likelihood writes down as the product of Bernoulli distributions (declaration process) 260 over all time steps and all fish (considered independent), marginalized over the 261 probability distribution of all possible hidden states defined from the product of 262 Multinomial distributions for the movement and mortality processes. The maximum 263 likelihood is estimated using the Maximization-Expectation algorithm (Choquet and 264 Nogue 2010).

265 A goodness-of-fit (GOF) test was conducted prior to model selection to check if our 266 release and recapture data met the assumption of a general model (the Arnason267 Schwarz Model, Pradel et al. 2003). We performed a GOF test using the U-CARE 268 software (version 2.2, Choquet et al. 2009). GOF tests a 'trap-dependence' effect by 269 comparing future recapture histories between individuals released on the current 270 occasion versus individuals released on a previous occasion, for all individuals that are 271 seen again (for more details on GOF test, see Appendix A). 
272 Model selection was used to assess which model formulation in Table 3 was the best 273 supported by the data. Model selection was based on the Akaike's information criterion 274 corrected for overdispersion (QAIC). The model with the lowest score of QAIC is 275 considered as the best model. Only models with the same dataset (same length of time 276 series of data) were compared together.

\section{$277 \quad 2.4 .5$ Sensitivity to area boundaries}

278 A sensitivity analysis to the delineation of the areas was performed through a buffering 279 method consisting in removing fish released and recovered at or near a border. Such 280 individuals were potentially crossing the border using migration paths shorter than those 281 for centrally-based fish, creating a potential edge effect and introducing bias 282 (i.e. overestimation of movements among spatial areas) in estimates of movement 283 probabilities. We computed a $30 \mathrm{~km}$ buffer around each boundary to remove a 284 substantial amount (i.e. 10\%) of released and recovered fish inside the buffer (3364 fish 285 were removed).

\section{RESULTS}

287 The GOF test performed on the full dataset (from 1970 to 2018) revealed a lack of fit $\left(\chi^{2}\right.$ $288=57.476, \mathrm{P}=0.000$ and $\mathrm{df}=24)$ when over-dispersion is not accounted for. An 289 overdispersion coefficient $(\hat{c})$ of 2.39 was applied to all models to account for 290 overdispersion ( $\hat{c}$ superior to one, Burnham and Anderson 2003, Choquet et al. 2009).

291 Overall, the full model (model 1, Table 3 ) best explains the tagging-recovery data 292 including seasonal movements, specific declaration rate for each release experiment, 293 and fishing mortality varying across space and time. 
294 The data also support the hypotheses of different detection rates per release 295 experiments (QAIC model $1<$ QAIC model 3, Table 3) with the lowest declaration rates 296 estimated for the $\mathrm{CEFAS}_{2002}$, comparable detection rate between IFREMER $_{1976}$ and 297 IFREMER 2016 experiments and a relatively high detection rate for the CEFAS $_{1970}$ release 298 experiment. Declaration rate estimates presented in Figure 6 for model 1 were similar 299 among models 1, 2 and 4-7 (Supplementary Files; Table S1).

300 Even if the estimated movement's probabilities between areas remain overall very low, 301 the results support the existence of seasonal movements (Figure 7 and Figure S2 in 302 Supplementary Files for a focus on movement between areas). Furthermore, the 303 conclusion that the data support the existence of seasonal movements patterns is robust 304 to changes in the time series of fishing mortality used as input to the model. Indeed, 305 models with seasonal movements in general presented better QAIC scores when 306 considering pairs of models with the same survival input (QAIC model $1<$ QAIC model 307 2; QAIC model 4 < QAIC model 5; Table 3).

308 Overall, the results support the hypothesis of very low connectivity between the different 309 areas (model 1, Figure 7). For most areas and seasons, estimates of movement 310 probability are very low, if not null (i.e. probabilities of staying in the areas of origin are 311 close to one). Virtually no emigration is estimated from the NS and WC to the three 312 areas of the EEC. This result highlights the primarily residential nature of the adult 313 component of the common sole population, with only a very small proportion of adult fish 314 migrating among areas. Low probabilities of movement are estimated $\left(\Phi_{i, j}<0.25\right)$ for 315 fish in the UK and FrE areas which move to WC and NS. Thus low to moderate exports 316 outside of the EEC occur between the overwintering and spawning season. Low 317 probabilities of emigration from the FrW to the WC is also estimated between spawning 
318 and foraging seasons. Movement probabilities estimated with model 2 (no seasonal

319 variability of movements) also support the hypothesis of very low dispersion of common 320 sole between areas (Supplementary Files; Figure S2). Results are also robust to the 321 delineation of the five areas. The analysis performed on a dataset without fish released 322 and recovered near a border provided results (Supplementary Files; Figure S3) 323 comparable to those obtained with no buffering (Supplementary Files; Tables S2, S3 324 and S4).

325 Finally, the conclusion that very low connectivity exists between areas is robust to the 326 time series of data considered. No strong differences exist between movement 327 probability estimates obtained with the whole dataset (1970-2018), and with the shorter 328 time series 1970-1998, corresponding to historical release experiments (CEFAS 1970 and 329 IFREMER ${ }_{1976}$; Tables S2, S3 and S4 in Supplementary Files). Movement probability 330 between the FrE and NS areas is an exception. Between these areas, higher 331 movements are estimated when considering historical release experiments only. 332 Between foraging and overwintering seasons, all fish from NS move to FrE (Table S3), 333 whereas from spawning to foraging and overwintering to spawning seasons all fish from 334 the FrE move to NS (Supplementary Files; Table S2). However, these estimated 335 probabilities of movements can be explained by the small amount of fish released and 336 recovered in the FrE area: 82 over the 1970-1998 period in comparison with the 1307 337 fish released and recovered in the NS in the most recent period. Movement probabilities 338 inferred from recent tagging data collected from 2002 to 2018 are similar to the ones 339 estimated with the entire dataset (Supplementary Files; Tables S2, S3 and S4), with only 340 small movements among areas. There are however small differences in estimates of 341 movement probabilities between the recent tagging data and the full-time series, which 
342 mostly concern the three areas of the EEC. Between the foraging and overwintering 343 seasons, higher than average movement probability are estimated from the UK to the 344 FrE areas, as well as from the FrW to the FrE areas (Supplementary Files; Table S2). 345 Limited movements are also estimated from the FrE to the WC and FrW areas from 346 spawning to foraging seasons (Supplementary Files; Table S2). Confidence intervals are 347 greater for the more recent period than for 1970-2018 and 1970-1998 time series, 348 because of the smaller amount of fish released during CEFAS $_{2002}$ and IFREMER $_{2016}$ in 349 comparison with the CEFAS $_{1970}$ and IFREMER $_{1976}$ experiments (Table 3a).

3504 Discussion

351 In the present study, we have analyzed for the first time a substantive database of mark352 recapture data, with 32739 subadult and adult common sole being released over a 353 period of 49 years. Our results suggest minimal movements of sole among areas in the 354 EEC, and even lower immigration from adjacent areas, but low to moderate emigration 355 to the NS and to the WC, mainly between the overwinter and spawning seasons. Our 356 results provide evidence of low connectivity among common sole subpopulations within 357 the EEC, and no inputs from the adjacent spatial management areas. This evidence of 358 local segregation is consistent with recent studies using patterns in key life history traits 359 (Du Pontavice et al. 2018; Randon et al. 2018) for the common sole in the EEC.

360 Reliability of the estimates of movement

361 Commercially exploited fish populations are often widely monitored, which offers the 362 opportunity to use survey-generated estimates of population vital rates, expert 363 knowledge and/or stock assessment (McGarvey \& Feenstra 2002). In our study, we 364 used estimates of fishing and natural mortality from published stock assessments (ICES 
365 2017) as input fixed a priori in our state-space capture-mark-recapture modeling 366 approach. Models incorporating all data available on the survival process (e.g. yearly 367 and spatially varying fishing mortality) best explain the data.

368 Seasonal movement probabilities estimated in our study revealed low movements, with 369 small variations when considering different periods within the time series. However, the 370 historical release experiments $\left(\right.$ CEFAS $_{1970}$ and IFREMER $\left._{1976}\right)$ were not designed 371 specifically to study movement patterns at the scale of the English Channel, and 372 relatively little tagging effort was expended in the two areas along the French coast (FrW 373 and FrE). This deficit of data in the oldest release experiments can explain the difference 374 in movement parameters estimated for the 1970 to 1998 time series with regards to the 375 full time series or to the recent release experiment. Only the recent release experiments $376\left(\mathrm{CEFAS}_{2002}\right.$ and IFREMER $\left._{2016}\right)$ sampled all three EEC areas more evenly. Jointly 377 analyzing all four tagging experiments allowed for a more balanced dataset, and 378 reduced singularities and potential bias incorporated by the spatial locations of fish 379 releases between release experiments.

380 We recognize, however, some weaknesses in our approach, some of which open up 381 exciting opportunities for future research. Our model is structured on a seasonal time 382 step of 4-months that reflect biological seasons of the life cycle of the sole in the Eastern 383 Channel. Although this is justified from a biological point of view, this choice excludes 384 data from fish that were released and recovered within the same seasonal time step. 385 The percentage of fish removed because of the chosen time step remains low $(7 \%$ of 386 released fish). For those removed fish, $94 \%$ were recovered in their zone of release, in 387 accordance with the results obtained on a 4-monthly basis. In all models, mortality rates 388 (fishing and natural) were considered known and estimated parameters are the 
389 movement and declaration probabilities. Estimating movement, mortality and 390 detectability is possible in certain configuration of mark-recapture models (Royle et al. 391 2013) but separating temporal and spatial variations in those parameters is still difficult 392 overall. In our model, attempts to estimate both natural mortality and declaration rates 393 from our data have shown unstable numerical results and estimates that were non394 robust to small changes in hypotheses, revealing some statistical confusion between 395 mortality and declaration rates. In other terms, different combinations of mortality and 396 declaration rates provide the same likelihood for the data. Because the total mortality 397 estimated from statistical catch-at-age stock assessment models is robust (Quinn \& 398 Deriso 1999; ICES 2017), and because no expertize exists on the declaration rate, our 399 choice here was to consider mortality as known, and to estimate declaration rates from 400 the data. Although stock assessment results provide some measure of uncertainty about $401 f$ (confidence intervals), only point estimates were considered in our approach. This 402 simplification answers practical considerations as no methods exist to account for 403 uncertainty in $f$ using the E-SURGE software. However, we carefully assessed the 404 sensitivity of our results to the hypothesis made on the temporal and spatial variation of 405 the fishing mortality. Because temporal and spatial variation in $f$ are much higher than 406 estimation uncertainty (ICES 2017), the robustness of our results to those changes in $f$ 407 demonstrates the robustness of our inferences on movements to uncertainty about $f$.

408 However, estimates from stock assessment models (and especially fishing mortality) can 409 be sensitive to hypotheses made on the spatial structure of the population (see for 410 instance results by Archambault et al. 2016 on the same case study), and make 411 inferences on dispersion by using fixed $f$ from previous assessments that do not 412 consider dispersion to be an issue. This paper is an important step toward the 
413 construction of an integrated model to simultaneously estimate fishing mortality and 414 dispersion by integrating tagging data within the stock assessment model. Tagging data, 415 however, can have a complex structure, which when coupled with a poorly balanced 416 sampling design, can provide further challenge to obtaining robust statistical inferences 417 from tagging-integrated models (Maunder \& Punt 2013). Consequently, we attempted 418 here to develop a first analysis of the tagging data before integrating them in a more 419 complex structure.

420 Our approach also considers natural mortality to be constant in space and in time. In 421 stock assessment evaluations, natural mortality is usually fixed and the fishing mortality 422 is estimated relative to the fixed value of natural mortality (ICES 2017). Preliminary 423 exploration of the data (not shown) suggested that consideration of a higher value of $m$ 424 (but still considering $m$ to be constant in time and space) has a simple and intuitive 425 impact on estimates of declaration rates. Considering a higher value of $m$ leads to lower 426 estimates of declaration rates, as the same number of recorded marked fish must be 427 explained by a lower actual number of marked fish in the sea due to higher $m$. On the 428 opposite, considering a smaller value of $m$ leads to higher estimates of declaration rates.

429 The effect of introducing spatial heterogeneity in $m$ which is operationally challenging 430 was not tested here. However, there is no evidence of a spatially varying natural 431 mortality for the common sole in the English Channel. Consequently, our assumption of 432 constant natural mortality among areas was considered to be a realistic and 433 parsimonious modeling approach for the estimation of fish movement.

434 Although Du Pontavice et al. (2018) and Archambault et al. (2016) suggested 435 heterogeneity of fishing mortality within the EEC, with the fishing pressure in FrE being 436 higher than in the UK and FrW areas, no spatial variability of fishing mortality within the 
437 three EEC areas was considered in our approach. However, because the EEC common 438 sole stock is considered homogeneous, no stock assessment results were available for 439 the individual 'sub-stock' areas (UK, FrW, FrE), and no spatialized catch data were 440 available in the time series. Furthermore, although the fishery is strongly seasonal 441 (Vermard and Savina, com. pers.), available times series of within-year fishing effort 442 distribution were too short to be considered in our analysis (2000-2016 for French and 443 2004-2016 for foreign fleets), precluding the application of varying fishing mortality 444 between the 4-month 'seasons'. However, given (i) the very low level of dispersal 445 estimated among the different areas in the EEC and (ii) the high robustness of these 446 results to hypotheses on spatial and temporal variations in the fishing mortality that were 447 tested, it is unlikely that using more refined data would have dramatically altered the 448 conclusions. Furthermore, recapture probability in our approach depends only on $m$ and $449 f$. However because the fleet and associated gear is not routinely recorded for mark 450 recovery, heterogeneity due to the use of different fishing gears, which could have 451 introduced further realism to our model, was unable to be considered. Finally, we found 452 strong statistical evidence in favor of different declaration rates between the tagging 453 periods. Unfortunately, we were not able to find definitive explanations for those 454 differences. One potential explanation might be haphazard levels of communication with 455 the fishermen to publicize the tagging programs and associated rewards at different 456 periods in time. We considered the declaration rate to be homogeneous in time and 457 space within a period, which might have been a source of bias, in that different fleets 458 operating in different zones may not have had equivalent information, interest or 459 motivation to participate in scientific tagging programs. As a result, our estimated 460 movement probabilities may have been biased by reducing the number of declarations 
461 of marked fish caught in a particular area. We have assumed that the aggregation of 462 several tagging surveys from both UK and French research institutes in the present 463 modeling approach should limit the overall related biases.

464 Combining different approaches to improve estimates of connectivity

465 Several authors have recently highlighted the importance of combining multiple 466 approaches to study stock delineation (Pita et al. 2016). Indeed, individual methods 467 each have their own strengths and weaknesses, and combining results of different 468 methods generally improves the overall reliability of the results (Cadrin et al. 2014; Izzo 469 et al. 2017). For marine fish in particular, high mortality in early life stages (eggs, larvae 470 and juveniles, Le Pape and Bonhommeau 2015) and the lack of barriers in the ocean 471 often rend the genetic signal of segregation relatively weak (Selkoe et al. 2008). Only a 472 very small proportion of fish dispersing at each generation will erase genetics 473 differences between populations (Palmer et al. 2014), which can result in a mismatch 474 between ecological and genetic connectivity (Hawkins et al. 2016).

475 The common sole stocks in the English Channel and North Sea are recognized as 476 genetically distinct populations (Diopere et al. 2017) and have been managed separately 477 for decades. While common sole in the EEC has been managed as a single 478 homogeneous stock unit thus far, evidence from different approaches is now 479 accumulating in support of considering spatial structure at a finer scale. Here we 480 demonstrate very low exchanges between the three delineated EEC areas, and virtually 481 no immigration from adjacent stocks. This demographic isolation is consistent with the 482 marked discrepancies in growth between the areas (Du Pontavice et al. 2018; Randon 483 et al. 2018) and the lasting synchrony among density-at-age time series inside each 484 area (Randon et al. 2018). 


\section{From low adult-mediated connectivity to segregation in EEC areas}

486 In the EEC, larval connectivity of the common sole is low, since spawning areas directly 487 feed adjacent coastal nursery grounds (Rochette et al. 2012). After metamorphosis, 488 juveniles grow on shallow nursery grounds (Riou et al. 2001; Rochette et al. 2010). 489 Limited movements of juvenile flatfish (Le Pape \& Cognez 2016), and the dependence 490 of the juvenile common sole upon shallow nursery habitats (Riou et al. 2001) result in 491 low juvenile connectivity (Coggan \& Dando 1988). After about two years on nursery 492 grounds, the common sole move to deeper offshore adult foraging grounds. In addition 493 to premature segregation, the lack of connectivity during the adult phase is a potentially 494 important driver of segregation (Frisk et al. 2014). However, estimated levels of 495 dispersal demonstrate that at subadult and adult stages, EEC export a low fraction of 496 individuals to the NS and a very low fraction to the WC. The EEC may act as a limited 497 source of fish for these adjacent stocks. These movements occur mainly during the 498 overwintering period of movements of subadults (Dorel et al. 1991) and adults (Horwood 499 1993; Burt \& Millner 2008) when common sole move out towards deeper sea areas.

\section{Management implications}

501 Ignoring the spatial structure of exploited fish population dynamics may induce 502 mismatches between the stock units considered for stock assessment and management 503 and the biological population structure (Carson et al. 2011; Frisk et al. 2014; Kerr et al. 504 2017). A better consideration of the spatial structure of populations and of 505 metapopulation dynamics is critical for sound evidence-based decision-making (Heino et 506 al. 1997; Porch et al. 1998; Ulrich et al. 2017). Inconsistencies between the spatial 507 structure of populations and delineation of stock units could impede effectiveness and 508 appropriateness of management measures (Kerr et al. 2017), resulting in the 
509 overexploitation of the less productive subunits (Cadrin \& Secor 2009; Ying et al. 2011;

510 Goethel \& Berger 2017). Adults' movements play a critical role in population connectivity

511 (Frisk et al. 2014), especially for species with a low level of connectivity at previous life

512 stages. Failure to appropriately consider the role of adults' movements (or local 513 segregation) can lead to bias in assessment of stock status and the proposal of 514 management non-adapted to the true dynamics and productivity of stocks (Punt \& 515 Restrepo 1995; Porch et al. 1998).

516 Rochette et al. (2013) and Archambault et al. (2016) have developed an integrated life 517 cycle Bayesian model of the EEC common sole stock. The life cycle sequentially 518 considers the production of eggs by adults, larval survival and drift, survival and 519 settlements in coastal nurseries, habitat-dependent survival of juveniles on nurseries 520 and finally natural and fishing mortality of the adult population. Archambault et al. (2016) 521 consider two contrasted hypotheses: (i) one single homogeneous adult population 522 supplemented by all coastal nurseries; (ii) three isolated subpopulation supplemented by 523 separated pools of coastal nurseries. Results show that accounting for spatial 524 segregation markedly influences stock assessment results (Archambault et al. 2016). 525 Results, from both this and the previous study, show that estimates of fishing mortality 526 and management reference points such as MSY of the common sole in the EEC 527 strongly depend upon the underpinning hypothesis of adult connectivity. Further 528 extension of the integrated life cycle modeling framework of Archambault et al. (2016) to 529 integrate the analysis of tagging data within the integrated life cycle model would allow 530 the simultaneous estimation of fishing mortality in the different areas of the EEC and 531 connectivity between those areas. We suggest that such an exercise would contribute to 
532 improving scientific advice for the spatial management of the fishery (Methot 2009;

533 Goethel et al. 2011; Griffiths et al. 2018).

\section{ACKNOWLEDGEMENT}

535 We would like to thank Coline Lazard, Sophie Parrad, Nicolas Goascoz, Ronan Lebras,

536 David Osmond and Yves Verin for their extensive involvement in the tagging program.

537 We also thank Elodie Réveillac for fruitful discussions about ecological concepts and the 538 Associate Editor and two anonymous referees for their useful comments in the review 539 process.

\section{FUNDING}

541 This work is part of the SMAC (Sole de Manche Est Amélioration des Connaissances

542 pour une meilleure gestion du stock) research program. This work is supported by the 543 fisheries organization "France Filière Pêche" and the French Ministry in charge of 544 fisheries "Direction des Pêches Maritimes et de l'Aquaculture". 
$547 \quad$ Table 1: Number of marked and recovered fish, used in the analysis, per release 548 experiment and associated average time at liberty in number of 4-month periods and 549 recapture rates.

\begin{tabular}{cllll}
\hline Experiment & Marked & Recovered & Average time at liberty & Recapture rate \\
\hline CEFAS $_{1970}$ & 3627 & 3627 & 6.26 & 1 \\
IFREMER $_{1976}$ & 305 & 305 & 4.07 & 1 \\
CEFAS $_{2002}$ & 29 & 29 & 5.59 & 1 \\
IFREMER $_{2016}$ & 85 & 85 & 3.07 & 1 \\
Total & 4046 & 4046 & 6.02 & 1 \\
\hline
\end{tabular}


550

551 Table 2: Number of fish released per area and time series and in parentheses the 552 number of recovered fish per area and time series.

\begin{tabular}{lllll}
\hline & Areas & $1970-1998$ & $2002-2018$ & $1970-2018$ \\
\hline 1 & WC & $5025(949)$ & $250(10)$ & $5275(959)$ \\
2 & UK & $6897(1298)$ & $1861(13)$ & $8758(1311)$ \\
3 & FrW & $1448(90)$ & $1048(7)$ & $2496(97)$ \\
4 & FrE & $1143(93)$ & $2148(55)$ & $3291(148)$ \\
5 & NS & $12509(1505)$ & $410(16)$ & $12919(1521)$ \\
6 & Total & $27022(3935)$ & $5717(101)$ & $32739(4036)$ \\
\hline
\end{tabular}

553

554 
555 Table 3: Model definition. Models 1 to model 7 are fitted to the full time series. Model 1 is 556 the most complex model. Model selection is performed on the full dataset (1970 to 2018)

557 from model 1 to less complex alternatives in the dispersal, fishing mortality inputs and 558 detection rates. $\triangle$ QAIC represents the difference in QAIC in comparison to model 1. 559 Models 8 and 9 have the same structure as model 1, but are fitted to truncated time $560 \quad$ series and hence are not considered in the model selection process.

\begin{tabular}{cclllll}
\hline Model & Dispersal & Fishing mortality & Detection & Time Series & QAIC & LQAIC \\
\hline 1 & Seasonal & Area x Years & Release experiments & $1970-2018$ & 144966 & - \\
2 & Constant & Area x Years & Release experiments & $1970-2018$ & 144976 & 10 \\
3 & Seasonal & Area x Years & Unique & $1970-2018$ & 145882 & 916 \\
4 & Seasonal & Area & Release experiments & $1970-2018$ & 145156 & 190 \\
5 & Constant & Area & Release experiments & $1970-2018$ & 145187 & 221 \\
6 & Seasonal & Homogeneous & Release experiments & $1970-2018$ & 145148 & 182 \\
7 & Constant & Homogeneous & Release experiments & $1970-2018$ & 145132 & 166 \\
8 & Seasonal & Area x Years & Release experiments & $1970-1998$ & - & - \\
9 & Seasonal & Area x Years & Release experiments & $2002-2018$ & - & - \\
\hline
\end{tabular}


561

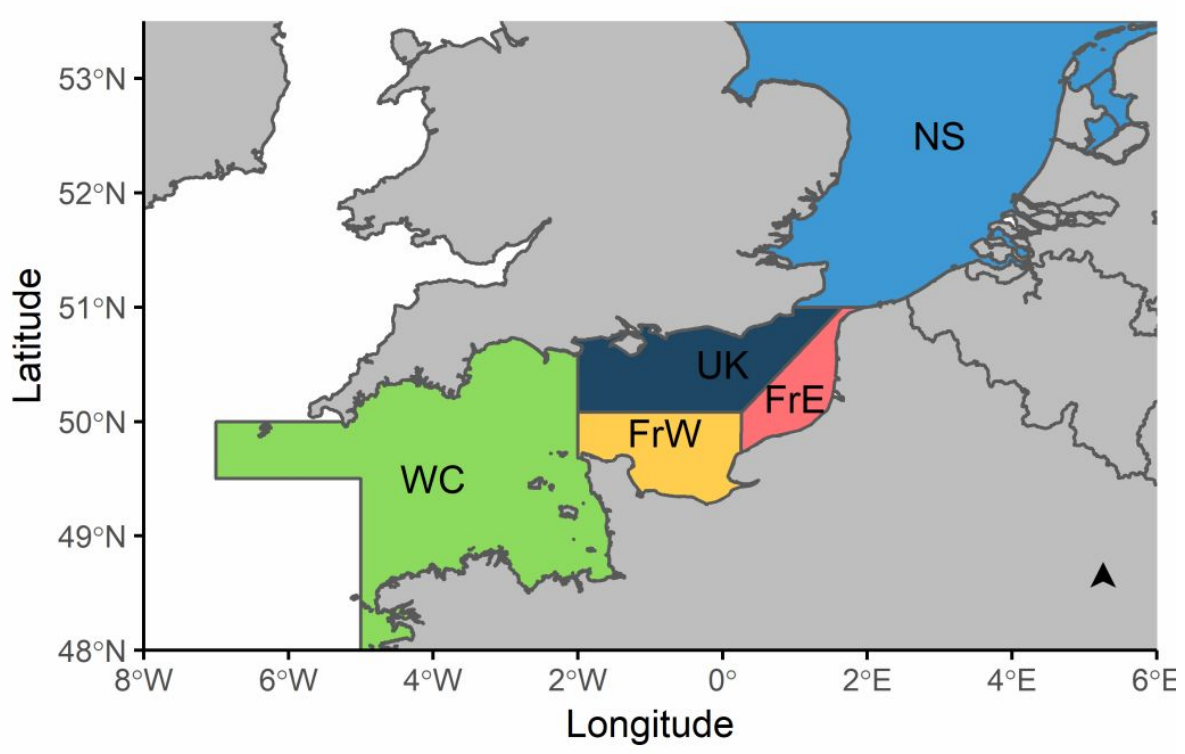

562

563

564

565

566

567

568

Figure 1: Map of the model geographical definition with the five areas potentially structuring common sole stocks (ICES. 2017; IFREMER 2019): Western Channel (WC, ICES division VIle), English coast of the Eastern English Channel (UK, ICES division VIId), Southern French coast (FrW, ICES division VIId), Northern French coast of the Eastern English Channel (FrE, ICES division VIId) and the southern part of the North Sea (NS, ICES division IVc).

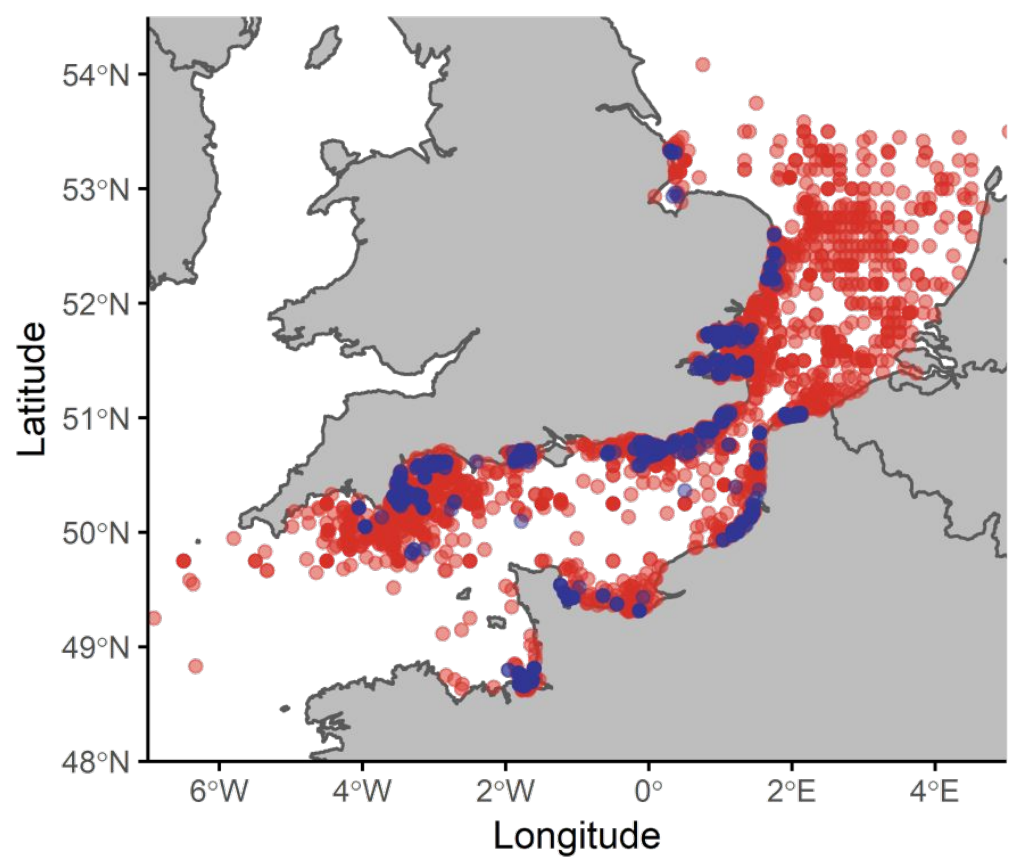

569

570 Figure 2: Release locations (in blue) and recapture locations (in red) of tagged common 571 sole in the English Channel, east of the Western Channel and west of North Sea (Burt \& 572

Millner 2008; IFREMER 2019). 


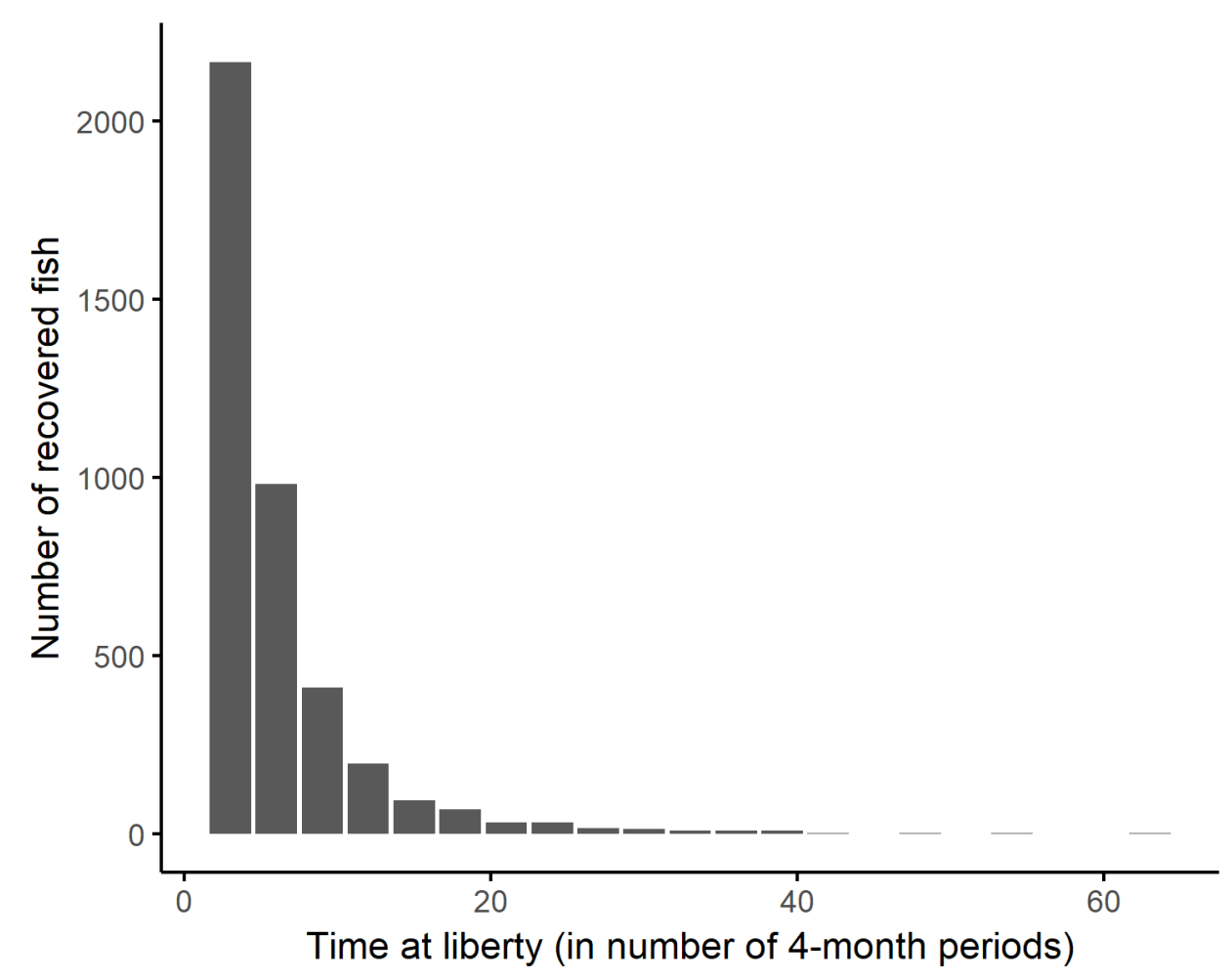

Figure 3: Time at liberty in number of seasons (4-month periods) for the 4036 marked fish recovered between 1970 and 2018. 


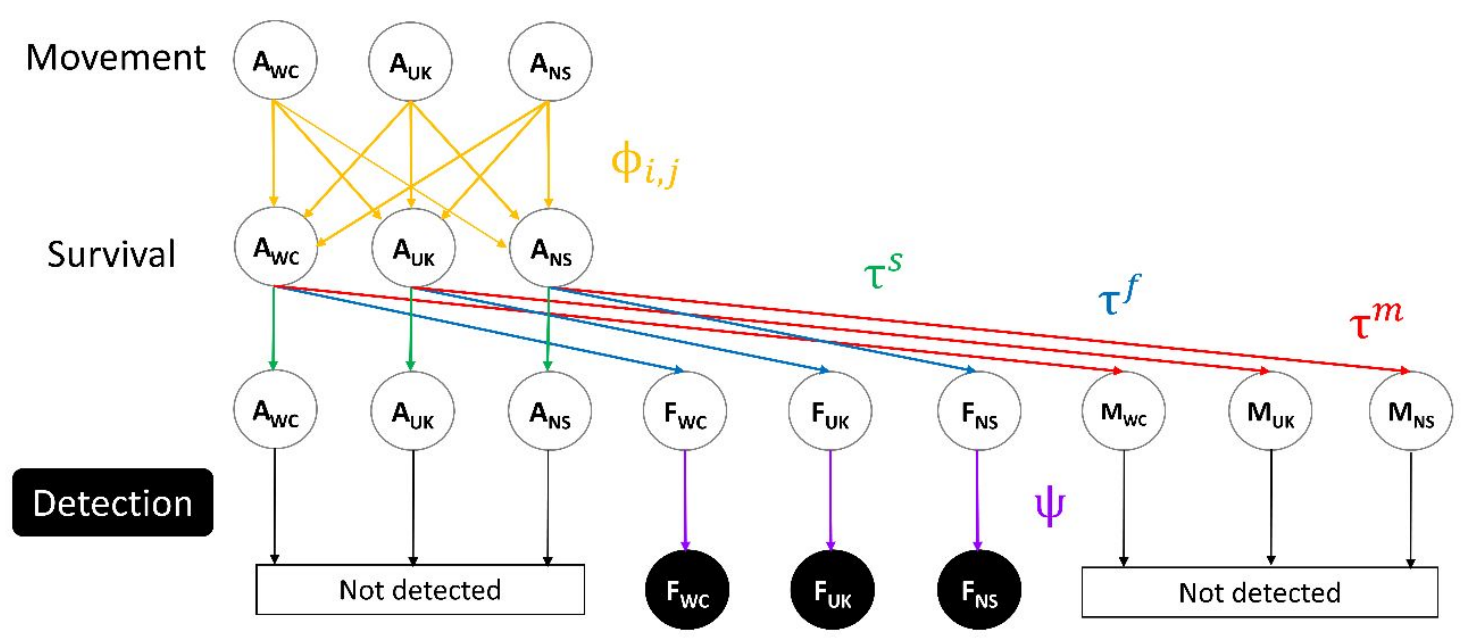

580

$581 \quad$ Figure 4: Diagram representing the model structure used in the analysis. Each step 582 represents a different model parameter or transition probability. Only three (WC, UK, $583 N S)$ of the five areas are represented for ease of reading. Live fish $\left(A_{W C}, A_{U K}, A_{N S}\right)$ and 584 fish dying due to natural causes $\left(M_{W C}, M_{U K}, M_{N S}\right)$ cannot be seen and hence cannot be 585 detected. 


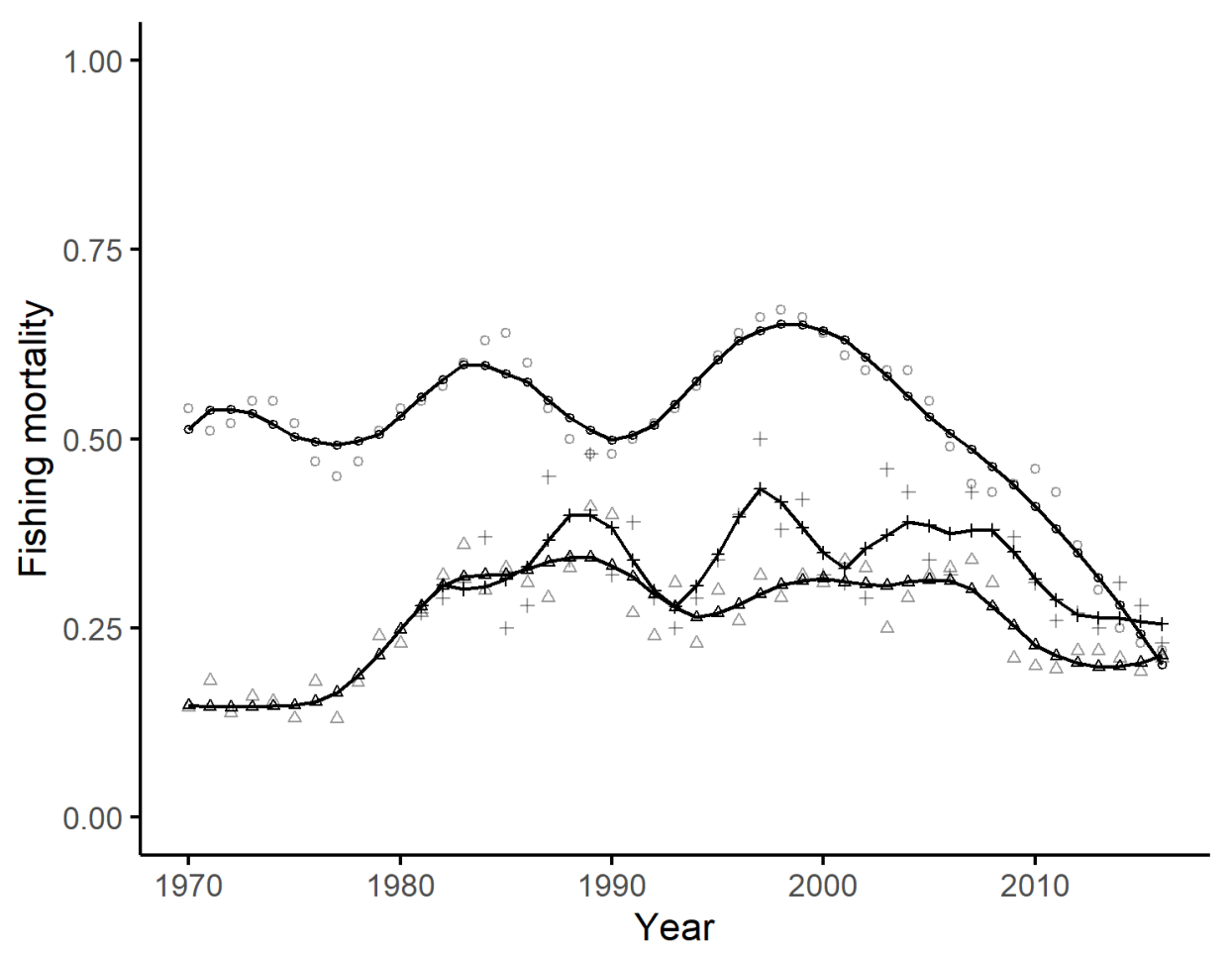

588

589 Figure 5: Annual fishing mortality rate estimated from stock assessments (ICES 2017). 590 Dotted line represents $f$ for area IV, triangle line represents $f$ for area VIId, and cross591 line is for area VIle. Shaded triangle, dot and cross represent estimates from stock 592 assessment without smoothing. Locally weighted least squares regression was used to 593 perform smoothing with $30 \%$ of smoothing span. 


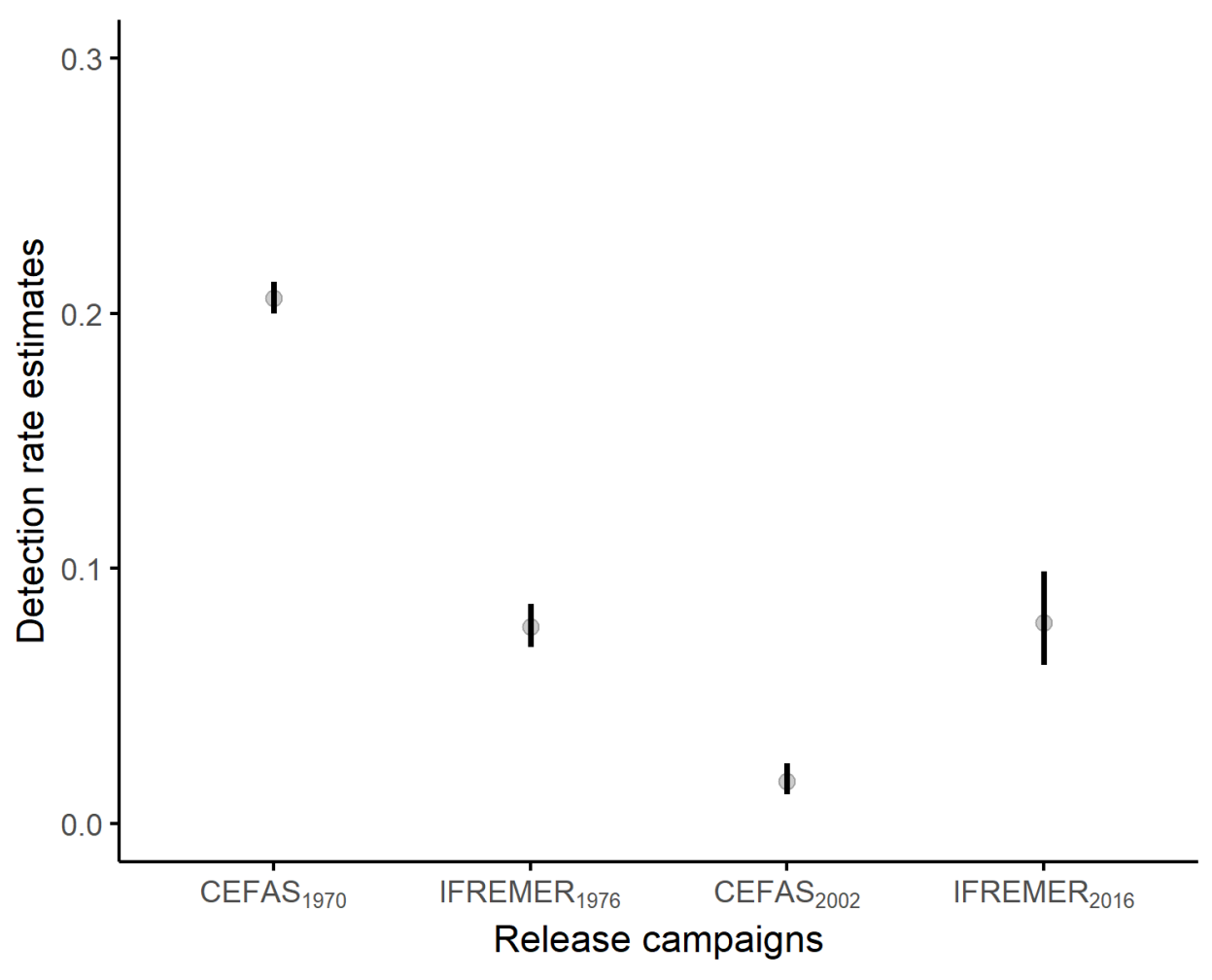

596 Figure 6: Detection rate $(\psi)$ estimates and their 95\% confidence intervals per release $597 \quad$ experiments from model 1 with the full time series (1970 to 2018). 


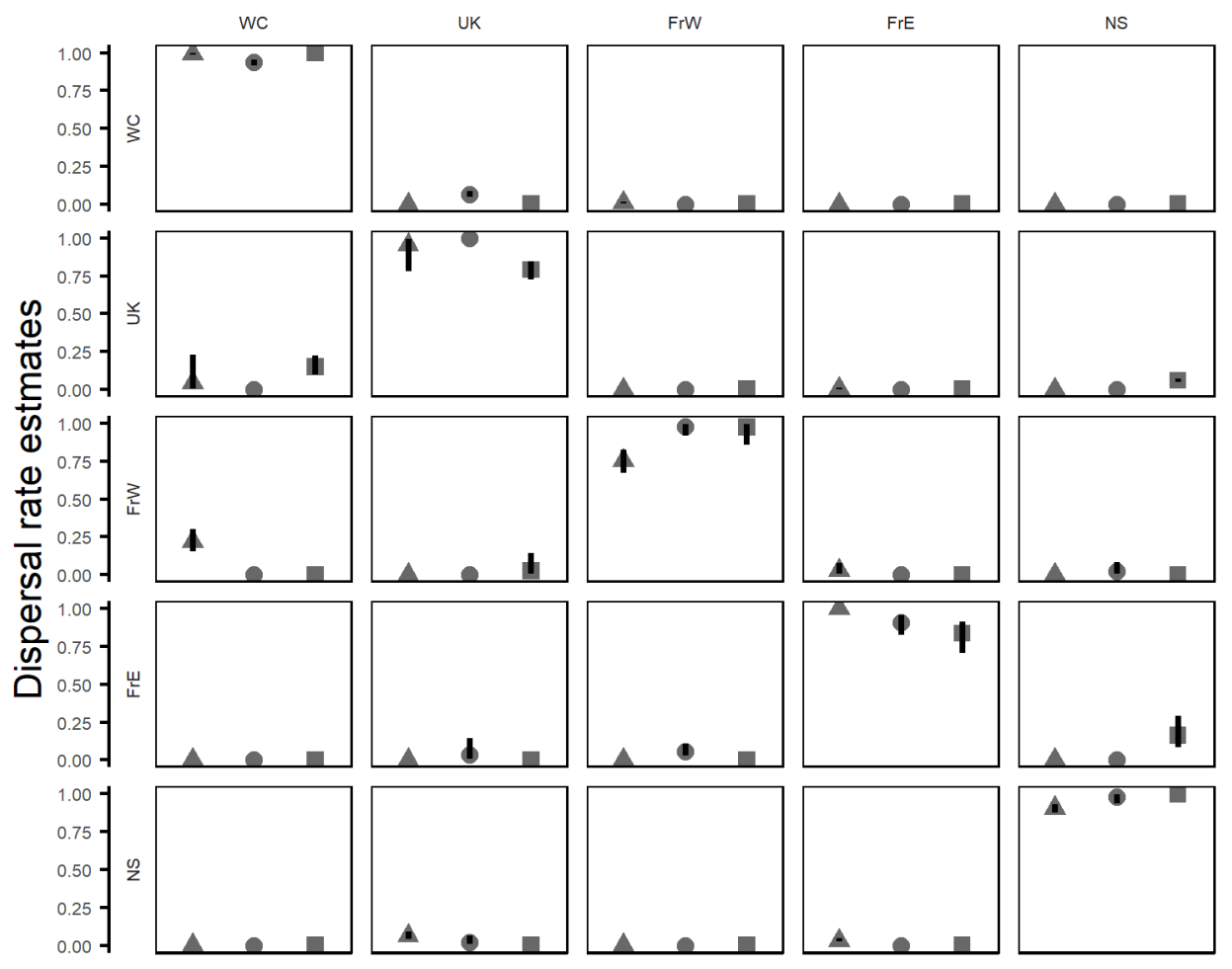

602 Figure 7: Movement probability estimates and their 95\% confidence intervals from model 603 1. Rows represent areas of departure and columns areas of arrival. Triangles are MLE 604 estimates of movement probabilities from spawning to foraging seasons. Circles from 605 foraging to overwintering seasons. Squares from overwintering to spawning season. 
618

619

620

621

622

623

624

625

626

627

628

629

630

631

632

633

634

635

636

637

638

639

640

641

642

643

644

645

646

647

648

649

650

651

652

653

654

655

\section{References}

Abaunza, P., Murta, A.G., Campbell, N., Cimmaruta, R., Comesaña, A.S., Dahle, G., Santamaría, M.G., Gordo, L.S., Iversen, S.A. \& MacKenzie, K. 2008. Stock identity of horse mackerel (Trachurus trachurus) in the Northeast Atlantic and Mediterranean Sea: Integrating the results from different stock identification approaches. Fisheries Research, 89, 196-209.

Adlerstein, S.A., Rutherford, E.S., Claramunt, R.M., Clapp, D.F. \& Clevenger, J.A. 2008. Seasonal movements of Chinook salmon in Lake Michigan based on tag recoveries from recreational fisheries and catch rates in gill-net assessments. Transactions of the American Fisheries Society, 137, 736-750.

Aeberhard, W.H., Mills Flemming, J. \& Nielsen, A. 2018. Review of State-Space Models for Fisheries Science. Annual Review of Statistics and Its Application, 5, 215-235.

Allaya, H., FALEH, A.B., Rebaya, M., Zrelli, S., Hajjej, G., Hattour, A., Quignard, J.-P. \& Trabelsi, M. 2016. Identification of Atlantic Chub Mackerel Scomber Colias Population through the Analysis of Body Shape in Tunisian Waters. Cah. Biol. Mar, 57, 195-207.

Archambault, B., Le Pape, O., Baulier, L., Vermard, Y., Véron, M. \& Rivot, E. 2016. Adult-mediated connectivity affects inferences on population dynamics and stock assessment of nursery-dependent fish populations. Fisheries research, 181, 198-213.

Bacha, M., Jeyid, A.M., Jaafour, S., Yahyaoui, A., Diop, M. \& Amara, R. 2016. Insights on stock structure of round sardinella Sardinella aurita off north-west Africa based on otolith shape analysis. Journal of fish biology, 89, 2153-2166.

Begg, G.A., Friedland, K.D. \& Pearce, J.B. 1999. Stock identification and its role in stock assessment and fisheries management: An overview. Fisheries Research, 43, 1-8.

Begg, G.A. \& Waldman, J.R. 1999. An holistic approach to fish stock identification. Fisheries Research, 43, 35-44.

Bekkevold, D., Helyar, S.J., Limborg, M.T., Nielsen, E.E., Hemmer-Hansen, J., Clausen, L.A.W. \& Carvalho, G.R. 2015. Gene-associated markers can assign origin in a weakly structured fish, Atlantic herring. ICES Journal of Marine Science, 72, 1790-1801.

Benhamou, S. 2014. Of scales and stationarity in animal movements. Ecology letters, $17,261-272$.

Burnham, K.P. \& Anderson, D.R. 2003. Model selection and multimodel inference: A practical information-theoretic approach. Springer Science \& Business Media.

Burt, G.J. \& Millner, R.S. 2008. Movement of sole in the southern North Sea and eastern English Channel from tagging studies 1955-2004. Science Series Technical Report, 44, $1-44$.

Cadigan, N.G. \& Brattey, J. 2006. Reporting and shedding rate estimates from tagrecovery experiments on Atlantic cod (Gadus morhua) in coastal Newfoundland. Canadian Journal of Fisheries and Aquatic Sciences, 63, 1944-1958. 
656 Cadigan, N.G. \& Brattey, J. 2003. Semiparametric estimation of tag loss and reporting 657 rates for tag-recovery experiments using exact time-at-liberty data. Biometrics, 59, 869658876.

659 Cadrin, S.X., Karr, L.A. \& Mariani, S. 2014. Stock Identification Methods: An Overview. 660 Stock Identification Methods (Second Edition), pp. 1-5. Elsevier.

661 Cadrin, S.X. \& Secor, D.H. 2009. Accounting for spatial population structure in stock 662 assessment: Past, present, and future. The future of fisheries science in North America, 663 pp. 405-426. Springer.

664 Callicó Fortunato, R., Reguera Galán, A., García Alonso, I., Volpedo, A. \& Benedito 665 Durà, V. 2017. Environmental migratory patterns and stock identification of Mugil 666 cephalus in the Spanish Mediterranean Sea, by means of otolith microchemistry. 667 Estuarine, Coastal and Shelf Science, 188, 174-180.

668 Carson, H.S., Cook, G.S., López-Duarte, P.C. \& Levin, L.A. 2011. Evaluating the 669 importance of demographic connectivity in a marine metapopulation. Ecology, 92, 19726701984.

671 Catalano, S.R., Whittington, I.D., Donnellan, S.C. \& Gillanders, B.M. 2014. Parasites as 672 Biological Tags to Assess Host Population Structure: Guidelines, Recent Genetic 673 Advances and Comments on a Holistic Approach. International Journal for Parasitology: 674 Parasites and Wildlife, 3, 220-226.

675 Choquet, R., Lebreton, J.-D., Gimenez, O., Reboulet, A.-M. \& Pradel, R. 2009. U-CARE: 676 677 Utilities for performing goodness of fit tests and manipulating CAptureREcapture data. Ecography, 32, 1071-1074.

Choquet, R. \& Nogue, E. 2010. E-SURGE 1.7 user's manual. CEFE, Montpellier.

Coggan, R.A. \& Dando, P.R. 1988. Movements of juvenile Dover sole, Solea solea (L.), In the Tamar Estuary, South-western England. Journal of Fish Biology, 33, 177-184.

Cuveliers, E.L., Larmuseau, M.H.D., Hellemans, B., Verherstraeten, S., Volckaert, F.A.M. \& Maes, G.E. 2012. Multi-Marker Estimate of Genetic Connectivity of Sole (Solea Solea) in the North-East Atlantic Ocean. Marine Biology, 159, 1239-1253.

Diopere, E., Vandamme, S.G., Hablützel, P.I., Cariani, A., Van Houdt, J., Rijnsdorp, A., Tinti, F., Consortium, F., Volckaert, F.A. \& Maes, G.E. 2017. Seascape genetics of a flatfish reveals local selection under high levels of gene flow. ICES Journal of Marine Science, 75, 675-689.

Dorel, D., Koutsikopoulos, C., Desaunay, Y. \& Marchand, J. 1991. Seasonal distribution of young sole (Solea solea (L.)) In the nursery ground of the Bay of Vilaine (Northern Bay of Biscay). Netherlands Journal of Sea Research, 27, 297-306.

Du Pontavice, H., Randon, M., Lehuta, S., Vermard, Y. \& Savina-Rolland, M. 2018. Investigating spatial heterogeneity of von Bertalanffy growth parameters to inform the stock structuration of common sole, Solea solea, in the Eastern English Channel.

694 Fisheries Research, 207, 28-36. 
695 Duriez, O., Saether, S.A., Ens, B.J., Choquet, R., Pradel, R., Lambeck, R.H.D. \& 696 Klaassen, M. 2009. Estimating survival and movements using both live and dead 697 recoveries: A case study of oystercatchers confronted with habitat change. Journal of 698 Applied Ecology, 46, 144-153.

699 Erlandsson, J., Östman, Ö., Florin, A.-B. \& Pekcan-Hekim, Z. 2017. Spatial structure of

700

701

702

703

704

705

706

707

708

709

710

711

712

713 body size of European flounder (Platichthys flesus L.) In the Baltic Sea. Fisheries Research, 189, 1-9.

Fernández-Chacón, A., Moland, E., Espeland, S.H., Kleiven, A.R. \& Olsen, E.M. 2016. Causes of mortality in depleted populations of Atlantic cod estimated from multi-event modelling of markRecapture and recovery data. Canadian journal of fisheries and aquatic sciences, 74, 116-126.

Fogarty, M.J. \& Botsford, L.W. 2007. Population connectivity and spatial management of marine fisheries. Oceanography, 20, 112-123.

Frisk, M.G., Jordaan, A. \& Miller, T.J. 2014. Moving beyond the current paradigm in marine population connectivity: Are adults the missing link? Fish and Fisheries, 15, 242 254.

Frusher, S.D., Frusher, S.D., Hoenig, J.M. \& Hoenig, J.M. 2001. Strategies for improving the precision of fishing and natural mortality estimates from multiyear tagging models: A case study. Marine and Freshwater Research, 52, 1649-1655.

714 Gauthier, G. \& Lebreton, J.-D. 2008. Analysis of band-recovery data in a multistate 715 capture-recapture framework. Canadian Journal of Statistics, 36, 59-73.

716

717

718

719

720

721

722

Gillanders, B.M., Ferrell, D.J. \& Andrew, N.L. 2001. Estimates of movement and lifehistory parameters of yellowtail kingfish (Seriola lalandi): How useful are data from a cooperative tagging programme? Marine and Freshwater Research, 52, 179-192.

723 Goethel, D.R., Quinn, T.J. \& Cadrin, S.X. 2011. Incorporating Spatial Structure in Stock 724 Assessment: Movement Modeling in Marine Fish Population Dynamics. Reviews in 725 Fisheries Science, 19, 119-136.

726 Griffiths, C.A., Patterson, T.A., Blanchard, J.L., Righton, D.A., Wright, S.R., Pitchford, 727 J.W. \& Blackwell, P.G. 2018. Scaling marine fish movement behavior from individuals to 728 populations. Ecology and evolution, 8, 7031-7043.

729 Hanselman, D.H., Heifetz, J., Echave, K.B. \& Dressel, S.C. 2014. Move it or lose it: 730 Movement and mortality of sablefish tagged in Alaska. Canadian Journal of Fisheries 731 and Aquatic Sciences, 72, 238-251.

732 Hanski, I. 1998. Metapopulation dynamics. Nature, 396, 41. 
733 Hawkins, S.J., Bohn, K., Sims, D.W., Ribeiro, P., Faria, J., Presa, P., Pita, A., Martins, 734 G.M., Neto, A.I., Burrows, M.T. \& Genner, M.J. 2016. Fisheries stocks from an 735 ecological perspective: Disentangling ecological connectivity from genetic interchange. 736 Fisheries Research, 179, 333-341.

737 Heino, M., Kaitala, V., Ranta, E. \& Lindström, J. 1997. Synchronous dynamics and rates 738 of extinction in spatially structured populations. Proceedings of the Royal Society of 739 London B: Biological Sciences, 264, 481-486.

740 Henny, C.J. \& Burnham, K.P. 1976. A reward band study of mallards to estimate band 741 reporting rates. The Journal of Wildlife Management, 1-14.

742 Hilborn, R. 1990. Determination of fish movement patterns from tag recoveries using 743 maximum likelihood estimators. Canadian Journal of Fisheries and Aquatic Sciences, 744 47, 635-643.

745 Horwood, J. 1993. The Bristol Channel sole (Solea solea (L.)): A fisheries case study. 746 Advances in Marine Biology, pp. 215-367. Elsevier.

747 Howe, A.B. \& Coates, P.G. 1975. Winter flounder movements, growth, and mortality off 748 Massachusetts. Transactions of the American Fisheries Society, 104, 13-29.

749 Hüssy, K., Mosegaard, H., Albertsen, C.M., Nielsen, E.E., Hemmer-Hansen, J. \& Eero, 750 M. 2016. Evaluation of Otolith Shape as a Tool for Stock Discrimination in Marine Fishes 751 Using Baltic Sea Cod as a Case Study. Fisheries Research, 174, 210-218.

752 ICES. 2017. Report of the Working Group on the Assessment of Demersal Stocks in the 753 North 685 Sea and Skagerrak. ICES HQ. ICES CM.

754 IFREMER. 2019. Sole de Manche Est : amélioration des connaissances pour une

755

756 meilleure gestion du stock. Rapport d'avancement du projet SMAC - année 3 Sole de Manche Est: amélioration des connaissances pour une meilleure gestion du stock.

Izzo, C., Ward, T.M., Ivey, A.R., Suthers, I.M., Stewart, J., Sexton, S.C. \& Gillanders, B.M. 2017. Integrated approach to determining stock structure: Implications for fisheries management of sardine, Sardinops sagax, in Australian waters. Reviews in Fish Biology and Fisheries, 27, 267-284.

Jasonowicz, A.J., Goetz, F.W., Goetz, G.W. \& Nichols, K.M. 2016. Love the One You're with: Genomic Evidence of Panmixia in the Sablefish (Anoplopoma Fimbria). Canadian Journal of Fisheries and Aquatic Sciences, 74, 377-387.

Kerr, L.A., Hintzen, N.T., Cadrin, S.X., Clausen, L.W., Dickey-Collas, M., Goethel, D.R., Hatfield, E.M.C., Kritzer, J.P. \& Nash, R.D.M. 2017. Lessons learned from practical approaches to reconcile mismatches between biological population structure and stock units of marine fish. ICES Journal of Marine Science, 74, 1708-1722.

Kutkuhn, J.H. 1981. Stock definition as a necessary basis for cooperative management of Great Lakes fish resources. Canadian Journal of Fisheries and Aquatic Sciences, 38, 1476-1478. 
771 Laconcha, U., Iriondo, M., Arrizabalaga, H., Manzano, C., Markaide, P., Montes, I., 772 Zarraonaindia, I., Velado, I., Bilbao, E., Goñi, N., Santiago, J., Domingo, A., Karakulak, 773 S., Oray, I. \& Estonba, A. 2015. New Nuclear SNP Markers Unravel the Genetic 774 Structure and Effective Population Size of Albacore Tuna (Thunnus alalunga). PLOS 775 ONE, 10, e0128247.

776 Lebreton, J.-D., Almeras, T. \& Pradel, R. 1999. Competing events, mixtures of 777 information and multistratum recapture models. Bird Study, 46, S39-S46.

778

779

780

781

782

Le Bris, A., Fisher, J.A., Murphy, H.M., Galbraith, P.S., Castonguay, M., Loher, T., Robert, D. \& Grabowski, H.e.J. 2017. Migration Patterns and Putative Spawning Habitats of Atlantic Halibut (Hippoglossus Hippoglossus) in the Gulf of St. Lawrence Revealed by Geolocation of Pop-up Satellite Archival Tags. ICES Journal of Marine Science, 75, 135-147.

783 Le Pape, O. \& Bonhommeau, S. 2015. The food limitation hypothesis for juvenile marine 784 fish. Fish and Fisheries, 16, 373-398.

785 Le Pape, O. \& Cognez, N. 2016. The range of juvenile movements of estuarine and 786 coastal nursery dependent flatfishes: Estimation from a meta-analytical approach. 787 Journal of Sea Research, 107, 43-55.

788 Liljestrand, E.M., Wilberg, M.J. \& Schueller, A.M. 2019. Multi-state dead recovery mark789 recovery model performance for estimating movement and mortality rates. Fisheries 790 Research, 210, 214-223.

791 MacKenzie, K. \& Abaunza, P. 2014. Parasites as Biological Tags. Stock Identification 792 Methods (Second Edition), pp. 185-203. Elsevier.

793 Mahe, K., Delpech, J.-P. \& Carpentier, A. 2007. Synthèse bibliographique des 794 principales espèces de Manche orientale et du golfe de Gascogne.

795

Mahe, K., Oudard, C., Mille, T., Keating, J., Gonçalves, P., Clausen, L.W., Petursdottir, G., Rasmussen, H., Meland, E. \& Mullins, E. 2016. Identifying Blue Whiting

797 (Micromesistius Poutassou) Stock Structure in the Northeast Atlantic by Otolith Shape 798 Analysis. Canadian journal of fisheries and aquatic sciences, 73, 1363-1371.

799 Marandel, F., Lorance, P., Andrello, M., Charrier, G., Le Cam, S., Lehuta, S. \& Trenkel, 800 V.M. 2017. Insights from genetic and demographic connectivity for the management of 801 rays and skates. Canadian Journal of Fisheries and Aquatic Sciences, 75, 1291-1302.

802 Martinez, E., Buonaccorsi, V., Hyde, J.R. \& Aguilar, A. 2017. Population genomics 803 reveals high gene flow in grass rockfish (Sebastes rastrelliger). Marine Genomics, 33, 804 57-63.

805 Maunder, M.N. \& Punt, A.E. 2013. A review of integrated analysis in fisheries stock 806 assessment. Fisheries Research, 142, 61-74.

807 McCrea, R.S. \& Morgan, B.J. 2014. Analysis of capture-recapture data. Chapman and 808 Hall/CRC. 
809 McGarvey, R. \& Feenstra, J.E. 2002. Estimating rates of fish movement from tag 810 recoveries: Conditioning by recapture. Canadian Journal of Fisheries and Aquatic 811 Sciences, 59, 1054-1064.

812 Methot, R.D. 2009. Stock synthesis (ver. 3.02 C). NOAA Fish. Tool.

813 Milano, I., Babbucci, M., Cariani, A., Atanassova, M., Bekkevold, D., Carvalho, G.R., 814 Espiñeira, M., Fiorentino, F., Garofalo, G. \& Geffen, A.J. 2014. Outlier SNP Markers 815 Reveal Fine-Scale Genetic Structuring across European Hake Populations (Merluccius 816 merluccius). Molecular Ecology, 23, 118-135.

817 Moreira, C., Froufe, E., Sial, A.N., Caeiro, A., Vaz-Pires, P. \& Correia, A.T. 2018. 818 Population Structure of the Blue Jack Mackerel (Trachurus Picturatus) in the NE Atlantic 819 Inferred from Otolith Microchemistry. Fisheries Research, 197, 113-122.

820 Östman, Ö., Olsson, J., Dannewitz, J., Palm, S. \& Florin, A.-B. 2017. Inferring spatial 821 structure from population genetics and spatial synchrony in demography of Baltic Sea 822 fishes: Implications for management. Fish and Fisheries, 18, 324-339.

823 Palmer, S.C.F., Coulon, A. \& Travis, J.M.J. 2014. Inter-individual variability in dispersal 824 behaviours impacts connectivity estimates. Oikos, 123, 923-932.

825 Patterson III, W.F., Watterson, J.C., Shipp, R.L. \& Cowan Jr, J.H. 2001. Movement of 826 tagged red snapper in the northern Gulf of Mexico. Transactions of the American 827 Fisheries Society, 130, 533-545.

828 Pita, A., Casey, J., Hawkins, S.J., Villarreal, M.R., Gutiérrez, M.-J., Cabral, H., Carocci, 829 F., Abaunza, P., Pascual, S. \& Presa, P. 2016. Conceptual and practical advances in 830 fish stock delineation. Fisheries Research, 173, 185-193.

831 Pollock, K.H., Hearn, W.S. \& Polacheck, T. 2002. A general model for tagging on 832 multiple component fisheries: An integration of age-dependent reporting rates and 833 mortality estimation. Environmental and Ecological Statistics, 9, 57-69.

834 Porch, C., Kleiber, P., Turner, S., Sibert, J., Bailey, R. \& Cort, J.L. 1998. The efficacy of 835 VPA models in the presence of complicated movement patterns. COLLECTIVE 836 VOLUME OF SCIENTIFIC PAPERS-INTERNATIONAL COMMISSION FOR THE 837 CONSERVATION OF ATLANTIC TUNAS, 50, 591-622.

838 Pradel, R., Gimenez, O. \& Lebreton, D. 2005. Principles and interest of GOF tests for 839 multistate captureRecapture models. Animal Biodiversity and Conservation, 16.

840 Pradel, R., Wintrebert, C.M. \& Gimenez, O. 2003. A proposal for a goodness-of-fit test to 841 the Arnason-Schwarz multisite capture-recapture model. Biometrics, 59, 43-53.

842 Punt, A.E. \& Restrepo, V.R. 1995. Some effects of ignoring mixing when managing fish 843 populations subject to limited mixing. ICES Long-term Management Measures Working 844 Group WP1.

845 Quinn, T.J. \& Deriso, R.B. 1999. Quantitative fish dynamics. Oxford University Press. 
846 Randon, M., Réveillac, E., Rivot, E., Pontavice, H.D. \& Pape, O.L. 2018. Could we 847 consider a single stock when spatial sub-units present lasting patterns in growth and 848 asynchrony in cohort densities? A flatfish case study. Journal of Sea Research.

849 Régnier, T., Augley, J., Devalla, S., Robinson, C.D., Wright, P.J. \& Neat, F.C. 2017. 850 Otolith chemistry reveals seamount fidelity in a deepwater fish. Deep Sea Research Part 851 I: Oceanographic Research Papers, 121, 183-189.

852 Riou, P., Pape, O.L. \& Rogers, S.I. 2001. Contribution respective de differentes 853 854 855

856 857 nourriceries cotieres aux populations adultes de sole et de plie: Etude par couplage de modeles lineaires generalises avec un systeme $d$ information geographique. Aquatic Living Resources, 2, 125-135.

Rochette, S. 2011. Effet des perturbations anthropiques sur la survie des juvéniles de poissons marins dans les nourriceries et conséquences sur les renouvellement des populations.: Application au stock de sole commune (Solea solea) en Manche Est. PhD Thesis thesis, Rennes, Agrocampus Ouest.

860 Rochette, S., Huret, M., Rivot, E. \& Pape, O.L. 2012. Coupling hydrodynamic and 861 individual-based models to simulate long-term larval supply to coastal nursery areas. 862 Fisheries Oceanography, 21, 229-242.

863 Rochette, S., Le Pape, O., Vigneau, J. \& Rivot, E. 2013. A hierarchical Bayesian model 864 for embedding larval drift and habitat models in integrated life cycles for exploited fish. 865 Ecological Applications, 23, 1659-1676.

866 Rochette, S., Rivot, E., Morin, J., Mackinson, S., Riou, P. \& Le Pape, O. 2010. Effect of 867 nursery habitat degradation on flatfish population: Application to Solea solea in the 868 Eastern Channel (Western Europe). Journal of sea Research, 64, 34-44.

869 Rogers, L.A., Storvik, G.O., Knutsen, H., Olsen, E.M. \& Stenseth, N.C. 2017. Fine-Scale 870 Population Dynamics in a Marine Fish Species Inferred from Dynamic State-Space 871 Models. Journal of Animal Ecology, 86, 888-898.

872 Royle, J.A., Chandler, R.B., Sollmann, R. \& Gardner, B. 2013. Spatial capture-recapture. 873 Academic Press.

874 Selkoe, K.A., Henzler, C.M. \& Gaines, S.D. 2008. Seascape genetics and the spatial 875 ecology of marine populations. Fish and fisheries, 9, 363-377.

876 Sley, A., Jawad, L.A., Hajjej, G., Jarboui, O. \& Bouain, A. 2016. Morphometric and 877 Meristic Characters of Blue Runner Caranx Crysos and False Scad Caranx Rhonchus 878 (Pisces: Carangidae) from the Gulf of Gabes, Tunisia, Eastern Mediterranean. Cah. Biol. 879 Mar, 57, 309-316.

880 Smith, P.J., Jamieson, A. \& Birley, A.J. 1990. Electrophoretic studies and the stock 881 concept in marine teleosts. ICES Journal of Marine Science, 47, 231-245.

882 Tanner, S.E., Reis-Santos, P. \& Cabral, H.N. 2016. Otolith Chemistry in Stock 883 Delineation: A Brief Overview, Current Challenges and Future Prospects. Fisheries 884 research, 173, 206-213. 
885 Ulrich, C., Hemmer-Hansen, J., Boje, J., Christensen, A., Hüssy, K., Sun, H. \& Clausen, 886 L.W. 2017. Variability and connectivity of plaice populations from the Eastern North Sea 887 to the Baltic Sea, part II. Biological evidence of population mixing. Journal of sea 888 research, 120, 13-23.

889 Ying, Y., Chen, Y., Lin, L. \& Gao, T. 2011. Risks of Ignoring Fish Population Spatial 890 Structure in Fisheries Management. Canadian Journal of Fisheries and Aquatic 891 Sciences, 68, 2101-2120.

892 Zemeckis, D.R., Martins, D., Kerr, L.A. \& Cadrin, S.X. 2014. Stock identification of 893 Atlantic cod (Gadus morhua) in US waters: An interdisciplinary approach. ICES Journal 894 of Marine Science, 71, 1490-1506. 


\section{ApPEndix A}

\section{MODEL STRUCTURE AND E-SURGE SPECIFICATION}

E-SURGE (Choquet \& Nogue 2010) is used to implement multi-event models which are defined by steps representing biological and observation process. Each process is associated to a row-stochastic matrix for which each row corresponds to a multinomial distribution. All cells probability in the same row must sum to one and so one parameter is defined as the complement of the others (i.e. $1-$ Sothers) and is denoted by the symbol $\star$ in the following matrices. Cells with probabilities fixed at 0 are denoted with a dash (-). Matrices rows correspond to the starting state and columns correspond to the arrival state. In our multi-event model, we consider 16 biological states to inform on the true fate of individuals at each occasion:

$$
\left\{A_{W C}, A_{U K}, A_{F r W}, A_{F r E}, A_{N S}, F_{W C}, F_{U K}, F_{F r W}, F_{F r E}, F_{N S}, M_{W C}, M_{U K}, M_{F r W}, M_{F r E}, M_{N S}, \dagger\right\}
$$

State $A$ relates to live fish, state $F$ relates to fish killed by fishing and state $M$ relates to fish dying of natural causes, all located respectively in areas WC, UK, FrW, FrE, NS (Figure 1). An extra state $\dagger$ is introduced to represent an unobservable dead state which discriminates between the "newly dead" fish from the unobservable "long-timedead" fish (Lebreton et al. 1999; Fernández-Chacón et al. 2016). This state is required to estimate the detection rate of fish caught by the fisheries and to distinguish the different causes of mortality. In practice, a fish, that died from fishing or natural causes at time step $t$, is assigned to the state "long time dead" at the time step $t+1$ and can not change of state afterwards.

\section{Initialization}


Table A1: Matrix I: initial state probabilities $(\pi)$ are assigned to alive state only, because tagging is performed on alive fish only.

\begin{tabular}{|c|c|c|c|c|c|c|c|c|c|c|c|c|c|c|c|}
\hline$A_{W C}$ & $A_{U K}$ & $A_{F r W}$ & $A_{F r E}$ & $A_{N S}$ & $F_{W C}$ & $F_{U K}$ & $F_{F r W}$ & $F_{F r E}$ & $F_{N S}$ & $M_{W C}$ & $M_{U K}$ & $M_{F r W}$ & $M_{F r E}$ & $M_{N S}$ & $\dagger$ \\
\hline$\star$ & $\pi$ & $\pi$ & $\pi$ & $\pi$ & - & - & - & - & - & - & - & - & - & - & - \\
\hline
\end{tabular}

Dispersal

The first five rows of matrix $D$ corresponds to fish that are alive at time $t$ and move (or not) during the transition to time $t+1$. For instance, $\phi_{W C, U K}$ is the probability for a fish in state $A_{W C}$ at time $t$ to move from the $W C$ area to the $U K$ area and be in state $A_{U K}$ at time step $t+1$. The last 10 rows correspond to fish that are dead and by definition cannot move to another area and hence cannot change state at time $t+1$.

Table A2: Matrix D: migration probabilities $\left(\Phi_{i, j}\right)$.

\begin{tabular}{|c|c|c|c|c|c|c|c|c|c|c|c|c|c|c|c|c|}
\hline & $A_{W C}$ & $A_{U K}$ & $A_{F r W}$ & $A_{F r E}$ & $A_{N S}$ & $F_{W C}$ & $F_{U K}$ & $F_{F r W}$ & $F_{F r E}$ & $F_{N S}$ & $M_{W C}$ & $M_{U K}$ & $M_{F r W}$ & $M_{F r E}$ & $M_{N S}$ & $5+$ \\
\hline$A_{W C}$ & $\star$ & $\phi_{W C, U K}$ & $\phi_{W C, F r u}$ & $\phi_{W C, F r E}$ & - & - & - & - & - & - & - & - & - & - & - & - \\
\hline$A_{U K}$ & $\phi_{U K, W C}$ & $\star$ & $\phi_{U K, F r W}$ & $\phi_{U K, F r E}$ & $\phi_{U K, N S}$ & - & - & - & - & - & - & - & - & - & - & - \\
\hline$A_{F r W}$ & $\phi_{F r W, W}$ & $\phi_{F r W, U i}$ & ᄎ & $\phi_{F r W, F r}$ & $\phi_{F r W, N}$ & - & - & - & - & - & - & - & - & - & - & - \\
\hline$A_{F r E}$ & $\phi_{F r E, W C}$ & $\phi_{F r E, U K}$ & $\phi_{F r E, F r v}$ & $\star$ & $\phi_{F r E, N S}$ & - & - & - & - & - & - & - & - & - & - & - \\
\hline$A_{N S}$ & - & $\phi_{N S, U K}$ & $\phi_{N S, F r W}$ & $\phi_{N S, F r E}$ & $\star$ & - & - & - & - & - & - & - & - & - & - & - \\
\hline$F_{W C}$ & - & - & - & - & - & 1 & - & - & - & - & - & - & - & - & - & - \\
\hline$F_{U K}$ & - & - & - & - & - & - & 1 & - & - & - & - & - & - & - & - & - \\
\hline$F_{F r W}$ & - & - & - & - & - & - & - & 1 & - & - & - & - & - & - & - & - \\
\hline$F_{F r E}$ & - & - & - & - & - & - & - & - & 1 & - & - & - & - & - & - & - \\
\hline$F_{N S}$ & - & - & - & - & - & - & - & - & - & 1 & - & - & - & - & - & - \\
\hline$M_{W C}$ & - & - & - & - & - & - & - & - & - & - & 1 & - & - & - & - & - \\
\hline$M_{U K}$ & - & - & - & - & - & - & - & - & - & - & - & 1 & - & - & - & - \\
\hline$M_{F r W}$ & - & - & - & - & - & - & - & - & - & - & - & - & 1 & - & - & - \\
\hline$M_{F r E}$ & - & - & - & - & - & - & - & - & - & - & - & - & - & 1 & - & - \\
\hline$M_{N S}$ & - & - & - & - & - & - & - & - & - & - & - & - & - & - & 1 & - \\
\hline$\dagger$ & - & - & - & - & - & - & - & - & - & - & - & - & - & - & - & 1 \\
\hline
\end{tabular}

Survival 
After movement, fish survive (or not) following the survival transition matrix $S . \tau^{f}$ is the probability of dying from fishing and $\tau^{m}$ fom natural causes. The first five rows of matrix $S$ corresponds to fish that are alive at time $t$ and can survive or not during the transition to time $t+1$. The last 10 rows correspond to fish that are 'long-time-dead'. $\tau^{f}$ and $\tau^{m}$ are input from external knowledge (see section 2.4.2., ICES 2017) and are not estimated from the tagging data in E-SURGE.

Table A3: Matrix S: calculation of survival probabilities with fishing mortality probabilities $\left(\tau^{f}\right)$ and natural mortality probabilities $\left(\tau^{m}\right)$. Survival probabilities are fixed parameters from stock assessment evaluation (ICES 2017).

\begin{tabular}{lllllllllllllllll}
\hline & $A_{W C}$ & $A_{U K}$ & $A_{F r W}$ & $A_{F r E}$ & $A_{N S}$ & $F_{W C}$ & $F_{U K}$ & $F_{F r W}$ & $F_{F r E}$ & $F_{N S}$ & $M_{W C}$ & $M_{U K}$ & $M_{F r W}$ & $M_{F r E}$ & $M_{N S}$ & $\dagger$ \\
$A_{W C}$ & $\star$ & - & - & - & - & $\tau^{f}$ & - & - & - & - & $\tau^{m}$ & - & - & - & - & - \\
$A_{U K}$ & - & $\star$ & - & - & - & - & $\tau^{f}$ & - & - & - & - & $\tau^{m}$ & - & - & - & - \\
$A_{F r W}$ & - & - & $\star$ & - & - & - & - & $\tau^{f}$ & - & - & - & - & $\tau^{m}$ & - & - & - \\
$A_{F r E}$ & - & - & - & $\star$ & - & - & - & - & $\tau^{f}$ & - & - & - & - & $\tau^{m}$ & - & - \\
$A_{N S}$ & - & - & - & - & $\star$ & - & - & - & - & $\tau^{f}$ & - & - & - & - & $\tau^{m}$ & - \\
$F_{W C}$ & - & - & - & - & - & - & - & - & - & - & - & - & - & - & - & 1 \\
$F_{U K}$ & - & - & - & - & - & - & - & - & - & - & - & - & - & - & - & 1 \\
$F_{F r W}$ & - & - & - & - & - & - & - & - & - & - & - & - & - & - & - & 1 \\
$F_{F r E}$ & - & - & - & - & - & - & - & - & - & - & - & - & - & - & - & 1 \\
$F_{N S}$ & - & - & - & - & - & - & - & - & - & - & - & - & - & - & - & 1 \\
$M_{W C}$ & - & - & - & - & - & - & - & - & - & - & - & - & - & - & - & 1 \\
$M_{U K}$ & - & - & - & - & - & - & - & - & - & - & - & - & - & - & - & 1 \\
$M_{F r W}$ & - & - & - & - & - & - & - & - & - & - & - & - & - & - & - & 1 \\
$M_{F r E}$ & - & - & - & - & - & - & - & - & - & - & - & - & - & - & 1 \\
$M_{N S}$ & - & - & - & - & - & - & - & - & - & - & - & - & - & - & - & 1 \\
$\dagger$ & - & - & - & - & - & - & - & - & - & - & - & - & - & - & - & 1 \\
\hline
\end{tabular}




\section{First encounter event}

This matrix is defined differently for the first encounter event (tag-release, $k=1$ ) than for the second encounter event (tag-recovery $k=2$ ).

Table A4: Matrix B: events and corresponding model states for the first encounter. Fish are captured in their respective area without errors.

\begin{tabular}{|c|c|c|c|c|c|c|c|c|c|c|c|}
\hline & $\begin{array}{l}\text { not } \\
\text { seen }\end{array}$ & $\begin{array}{l}\text { captured } \\
\text { WC }\end{array}$ & in & $\begin{array}{l}\text { captured } \\
\text { UK }\end{array}$ & in & $\begin{array}{l}\text { captured } \\
\text { FrW }\end{array}$ & in & $\begin{array}{l}\text { captured } \\
\text { FrE }\end{array}$ & in & $\begin{array}{l}\text { captured } \\
\text { NS }\end{array}$ & in \\
\hline$A_{W C}$ & - & 1 & & - & & - & & - & & - & \\
\hline$A_{U K}$ & - & - & & 1 & & - & & - & & - & \\
\hline$A_{F r W}$ & - & - & & - & & 1 & & - & & - & \\
\hline$A_{F r E}$ & - & - & & - & & - & & 1 & & - & \\
\hline$A_{N S}$ & - & - & & - & & - & & - & & 1 & \\
\hline$F_{W C}$ & 1 & - & & - & & - & & - & & - & \\
\hline$F_{U K}$ & 1 & - & & - & & - & & - & & - & \\
\hline$F_{F r W}$ & 1 & - & & - & & - & & - & & - & \\
\hline$F_{F r E}$ & 1 & - & & - & & - & & - & & - & \\
\hline$F_{N S}$ & 1 & - & & - & & - & & - & & - & \\
\hline$M_{W C}$ & 1 & - & & - & & - & & - & & - & \\
\hline$M_{U K}$ & 1 & - & & - & & - & & - & & - & \\
\hline$M_{F r W}$ & 1 & - & & - & & - & & - & & - & \\
\hline$M_{F r E}$ & 1 & - & & - & & - & & - & & - & \\
\hline$M_{N S}$ & 1 & - & & - & & - & & - & & - & \\
\hline$\dagger$ & 1 & - & & - & & - & & - & & - & \\
\hline
\end{tabular}




\section{Second encounter event}

The second elementary matrix presents the probability of each state given the observation for the second and solely encounter $(k=2)$. In the second encounter event, only fish caught by the fishery can be seen. The matrix contains the detection rates $\psi$ :

Table A5: Matrix B: events and corresponding model states for the second and solely encounter. Only fish captured by the fisheries can be recaptured. Detection rate $\psi$ is estimated from the data.

\begin{tabular}{|c|c|c|c|c|c|c|c|c|c|c|}
\hline & $\begin{array}{l}\text { not } \\
\text { seen }\end{array}$ & $\begin{array}{l}\text { captured } \\
\text { WC }\end{array}$ & in & $\begin{array}{l}\text { captured } \\
\text { UK }\end{array}$ & in & $\begin{array}{l}\text { captured } \\
\text { FrW }\end{array}$ & in & $\begin{array}{l}\text { captured } \\
\text { FrE }\end{array}$ & in & $\begin{array}{l}\text { captured } \\
\text { NS }\end{array}$ \\
\hline$A_{W C}$ & 1 & - & & - & & - & & - & & - \\
\hline$A_{U K}$ & 1 & - & & - & & - & & - & & - \\
\hline$A_{F r W}$ & 1 & - & & - & & - & & - & & - \\
\hline$A_{F r E}$ & 1 & - & & - & & - & & - & & - \\
\hline$A_{N S}$ & 1 & - & & - & & - & & - & & - \\
\hline$F_{W C}$ & $\star$ & $\psi$ & & - & & - & & - & & - \\
\hline$F_{U K}$ & $\star$ & - & & $\psi$ & & - & & - & & - \\
\hline$F_{F r W}$ & $\star$ & - & & - & & $\psi$ & & - & & - \\
\hline$F_{F r E}$ & $\star$ & - & & - & & - & & $\psi$ & & - \\
\hline$F_{N S}$ & $\star$ & - & & - & & - & & - & & $\psi$ \\
\hline$M_{W C}$ & 1 & - & & - & & - & & - & & - \\
\hline$M_{U K}$ & 1 & - & & - & & - & & - & & - \\
\hline$M_{F r W}$ & 1 & - & & - & & - & & - & & - \\
\hline$M_{F r E}$ & 1 & - & & - & & - & & - & & - \\
\hline$M_{N S}$ & 1 & - & & - & & - & & - & & - \\
\hline$\dagger$ & 1 & - & & - & & - & & - & & - \\
\hline
\end{tabular}




\section{GOODNESS-OF-FIT TEST}

Goodness-of-fit (GOF) tests are an important component of capture-recapture modeling: they are used to assess the accuracy of a model in capturing the variance of the data (Pradel et al. 2005). The GOF test is divided into two components the $3 G$ test, which compares the capture histories of newly-tagged and previously-tagged individuals released at the same time, and the $M$ component testing a trap-dependence effect by comparing future capture histories between individuals released on the current occasion versus individuals released on a previous occasion, for all individuals that are seen again. In our case study, the $3 G$ test does not exist, because our datasets only includes dead recoveries (Gauthier \& Lebreton 2008). The GOF test then relies on the M component only.

GOF is performed on a reduced model that considers parameters to be state and timedependent with only six states 'dead' or 'alive' in each area (Pradel et al. 2003; Duriez et al. 2009; Fernández-Chacón et al. 2016). GOF cannot handle multiple unobservable states and models with more than 10 different events. We then pooled together subareas of the EEC and summarized observations in seven types of events (not encountered $=0$, encountered alive in $W C=1$, recovered dead in $W C=4$, encountered alive in $\mathrm{EEC}=2$, recovered dead in $\mathrm{ECC}=5$, encountered alive in $\mathrm{NS}=3$, recovered dead in NS =6). The GOF test was conducted prior to model selection using the U-CARE software (version 2.2, Choquet et al. 2009). The GOF test performed on our data was significant relvealing a lack-of-fit $\left(\chi^{2}=57.476, \mathrm{P}=0.000\right.$ and $\left.\mathrm{df}=24\right)$ to the general Arnason-Schwarz model (Pradel et al. 2003). To address this $\chi^{2}$ of the GOF test divided by the total number of degrees of freedom, to correct for potential lack of fit (Burnham \& Anderson 2003; Choquet et al. 2009; Fernández-Chacón et al. 2016). 